\title{
Resveratrol Mitigates Sevoflurane-Induced Neurotoxicity by the SIRT1-Dependent Regulation of BDNF Expression in Developing Mice
}

\author{
Xiaole Tang, Yilin Zhao, Zhiqiang Zhou, Jing Yan, Biyun Zhou, Xiaohui Chi, Ailin Luo $\mathbb{D}$, \\ and Shiyong $\mathrm{Li}$
}

Department of Anesthesiology, Tongji Hospital, Tongji Medical College, Huazhong University of Science and Technology, 1095 Jiefang Avenue, Wuhan, 430030 Hubei, China

Correspondence should be addressed to Ailin Luo; alluo@hust.edu.cn and Shiyong Li; shiyongli@hust.edu.cn

Received 10 September 2019; Revised 14 December 2019; Accepted 18 January 2020; Published 19 February 2020

Academic Editor: Nadja Schroder

Copyright (C) 2020 Xiaole Tang et al. This is an open access article distributed under the Creative Commons Attribution License, which permits unrestricted use, distribution, and reproduction in any medium, provided the original work is properly cited.

\begin{abstract}
Various lines of evidence suggest that neonatal exposure to general anesthetics, especially repeatedly, results in neuropathological brain changes and long-term cognitive impairment. Although progress has been made in experimental models, the exact mechanism of GA-induced neurotoxicity in the developing brain remains to be clarified. Sirtuin 1 (SIRT1) plays an important role in synaptic plasticity and cognitive performance, and its abnormal reduction is associated with cognitive dysfunction in neurodegenerative diseases. However, the role of SIRT1 in GA-induced neurotoxicity is unclear to date. In this study, we found that the protein level of SIRT1 was inhibited in the hippocampi of developing mice exposed to sevoflurane. Furthermore, the SIRT1 inhibition in hippocampi was associated with brain-derived neurotrophic factor (BDNF) downregulation modulated by methyl-cytosine-phosphate-guanine-binding protein 2 (MeCP2) and cAMP response element-binding protein (CREB). Pretreatment of neonatal mice with resveratrol nearly reversed the reduction in hippocampal SIRT1 expression, which increased the expression of BDNF in developing mice exposed to sevoflurane. Moreover, changes in the levels of CREB and MeCP2, which were considered to interact with BDNF promoter IV, were also rescued by resveratrol. Furthermore, resveratrol improved the cognitive performance in the Morris water maze test of the adult mice with exposure to sevoflurane in the neonatal stage, without changing motor function in the open field test. Taken together, our findings suggested that SIRT1 deficiency regulated $\mathrm{BDNF}$ signaling via regulation of the epigenetic activity of $\mathrm{MeCP} 2$ and $\mathrm{CREB}$, and resveratrol might be a promising agent for mitigating sevoflurane-induced neurotoxicity in developing mice.
\end{abstract}

\section{Introduction}

Every year, millions of children undergo diagnostic or surgical procedures under general anesthesia globally, and the long-term potential neurotoxic effects of general anesthetics (GAs) on the infant brain is a worldwide concern. Solid evidence from rodent and nonhuman primate models has proved that exposure to GAs, especially to those targeting the $\gamma$-aminobutyric acid type A receptor and/or the $\mathrm{N}$ methyl-D-aspartate receptor, during the brain growth spurt period can cause neuroapoptosis, synaptic dysfunction, and long-term behavioral abnormality [1-10]. Although growing preclinical data has been accumulated, ambiguity still exists in clinical studies [11-15]. A few clinical trials showed that a single brief exposure to GAs during the early life did not increase the risk of neurocognitive impairment [16-21]. However, the secondary analysis of the Mayo Anesthesia Safety in Kids study suggested that exposure to multiple procedures under general anesthesia before the age of 3 was associated with a specific pattern of deficits in neuropsychological tests, which was corroborated in experimental models [22]. Although these findings could not show a direct causality 
between neuropsychological deficits and GA exposure, they presented some useful hints to further evaluate the effects of GA on the neurodevelopment of children.

$\mathrm{BDNF}$ is a pivotal regulator of neuronal survival and synaptic plasticity in the hippocampus and other regions of the developing brain $[23,24]$. It has been shown that BDNF plays an important role in the formation of certain types of learning, memory, and mood regulation [25, 26]. Previous studies have shown that neonatal exposure to isoflurane and propofol reduces the production of mature BDNF and thus triggers neuroapoptosis [1, 27-29]. Moreover, a persistent reduction in hippocampal BDNF levels in adult rats that were neonatally exposed to isoflurane results in the insufficient synthesis of synaptic proteins and contributes to the cognitive impairment. This effect is mediated by the occupation of the promoter region of exon IV of BDNF with transcriptional factors such as DNA methyltransferase 1, $\mathrm{MeCP} 2$, and histone deacetylase 2 [30]. However, it remains unclear how neonatal isoflurane exposure regulates the activity of these transcriptional factors.

SIRT1 is a nicotinamide-adenine dinucleotide-dependent deacetylase belonging to the class III histone deacetylase family. SIRT1 is indispensable for synaptic plasticity and cognitive function under physiological conditions [31, 32]. Furthermore, activation of SIRT1 with resveratrol, a natural polyphenol agonist of SIRT1, mitigated neuronal injury by regulating the expression of BDNF in animal models of neurodegenerative diseases [32-36]. In addition, resveratrol was also found to mitigate age-related cognitive deficits [37-39]. However, whether SIRT1 is involved in sevoflurane exposureinduced cognition impairment and whether resveratrol can provide neuroprotection against the neurotoxicity of sevoflurane still need to be further investigated.

In the present study, we aimed to examine the role of SIRT1 in long-term cognitive changes induced by neonatal exposure to sevoflurane. Moreover, we tested the hypothesis that resveratrol restored anesthesia-induced SIRT1 reduction and improved long-term cognitive performance by modulating its substrates (including MeCP2 and CREB) and further influencing BDNF signaling.

\section{Materials and Methods}

2.1. Mouse Anesthesia and Treatment. C57BL/6J mice at 1618 days of gestation were purchased from the Laboratory Animal Center of Tongji Medical College (Wuhan, China). The mice were kept in cages in suitable environmental conditions $\left(22-24^{\circ} \mathrm{C}, 12\right.$-hour light/dark cycle) and were put on a diet of commercial pellet, without water restrictions. Both female and male pups were used in the studies. All experiments were conducted in accordance with the National Institute of Health Guide for the Care and Use of Laboratory Animals. The committee of Tongji Medical College has approved the animal protocol.

As shown in Figure 1(a), the neonatal mice were assigned randomly to four groups: control plus DMSO, control plus resveratrol treatment, sevoflurane plus DMSO, and sevoflurane plus resveratrol. The mice in anesthesia groups received $3 \%$ sevoflurane plus $60 \%$ oxygen (balanced with nitrogen)
$2 \mathrm{~h}$ daily form postnatal day (P)6 to P8 in the induction chamber as previous studies described [40-42]. The induction flow rate was $2 \mathrm{~L} / \mathrm{min}$ for the first three minutes (for induction) and then $1 \mathrm{~L} / \mathrm{min}$ with the rest of the anesthesia (for maintenance). Mice in the control conditions were separated from dams for the same period of time and exposed to the control gas ( $60 \%$ oxygen balanced with nitrogen). The concentrations of sevoflurane and oxygen were continuously monitored with an infrared probe (Ohmeda S/5 Compact, Datex-Ohmeda, Louisville, CO) during anesthesia. The anesthesia chamber was kept in a homoeothermic incubator to maintain the experimental temperature at $32^{\circ} \mathrm{C} \pm 0.5^{\circ} \mathrm{C}$. Previous studies have confirmed that the anesthesia with $3 \%$ sevoflurane for $2 \mathrm{~h}$ did not significantly change $\mathrm{pH}$ values, oxygen partial pressure, or carbon dioxide partial pressure in young mice as compared to those in the control group. Therefore, blood gas analysis of the mice was not conducted in our studies. In the intervention studies, $100 \mathrm{mg} / \mathrm{kg}$ resveratrol (dissolved in DMSO and diluted with saline) was administrated intraperitoneally (i.p.) on P3, P4, P5, and $1 \mathrm{~h}$ prior to isoflurane or control gas exposure from P6 to P8. Mice in the control group received $50 \mu \mathrm{L}$ DMSO solution ( $30 \mu \mathrm{L}$ of DMSO dissolved in $1 \mathrm{~mL}$ of saline), which is the vehicle of resveratrol. The number of animals used in each group is reported in Supplementary Table 1.

2.2. Harvest of Brain Tissues. Mice were allowed to completely recover from anesthesia. One hour after the end of sevoflurane anesthesia on P8, the mice were euthanized and decapitated. For western blot analysis, the harvested hippocampus tissues were homogenized on ice using RIPA lysis buffer (150 mM sodium chloride, Triton X-100, 0.5\% sodium deoxycholate, $0.10 \%$ sodium dodecyl sulfate, and $50 \mathrm{mM}$ Tris, pH 8.0) plus $1 \mathrm{mM}$ PMSF, protease inhibitors (Promoter, Wuhan, China), and phosphatase inhibitors (Boster, Wuhan, China). The lysates were collected and centrifuged at $12,000 \mathrm{rpm}$ for $10 \mathrm{~min}$, and total protein was quantified with a BCA assay kit (Boster).

2.3. Primary Neurons and Cell Treatment. C57BL/6J mice (The Laboratory Animal Center of Tongji Medical College, China) at 16-18 days of gestation were euthanized with carbon dioxide. Embryonic hippocampi were dissected as previously described [43]. The neurons were digested with $0.05 \%$ trypsin for $30 \mathrm{~min}$ at $37^{\circ} \mathrm{C}$. Then, the dissociated cells were plated at a density of 100,000 cells/well in poly-Dlysine-coated 6-well plates with DMEM/F12 medium (Gibco, Waltham, USA) supplemented with $10 \%$ fetal bovine serum (Gibco, USA). Four hours after plating, the medium was replaced with serum-free B27/neurobasal medium. The medium was replaced every 3 days.

The neurons were randomly assigned to four groups: control plus DMSO, control plus resveratrol, sevoflurane plus DMSO, and sevoflurane plus resveratrol, to receive incubation of $0.1 \%$ DMSO (the vehicle of resveratrol), $20 \mu \mathrm{M}$ resveratrol, $0.1 \% \mathrm{DMSO}$, and $20 \mu \mathrm{M}$ resveratrol, respectively, at the sixth day of culture for $24 \mathrm{~h}$. After seven days of plating, the neurons received $4.1 \%$ sevoflurane or control gas $(21 \%$ 


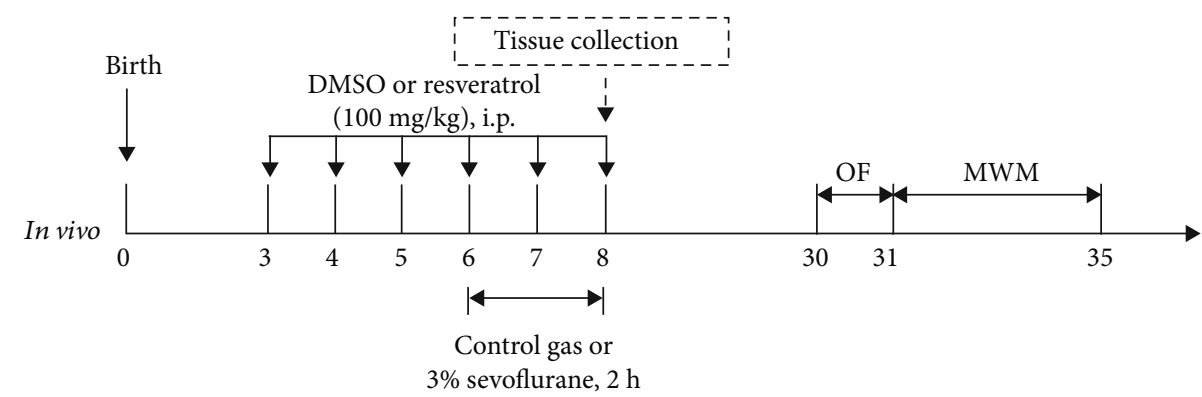

(a)

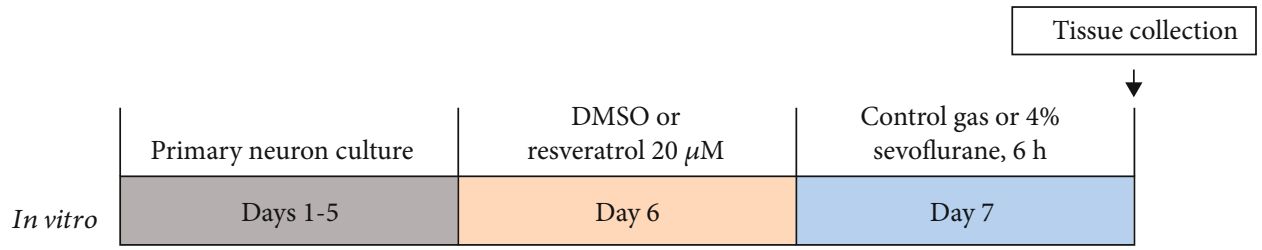

(b)

FIGURE 1: Experiment protocol in vivo and in vitro. (a) In vivo: 3-day-old mice were pretreated with DMSO or resveratrol via intraperitoneal injection daily for 6 consecutive days and received control gas exposure or $3 \%$ sevoflurane for $2 \mathrm{~h}$ from P6 to P8. After exposure, some of the mice were decapitated and tissue samples were collected for RT-PCR and western blotting; the other mice were returned to dams and received the OF test and MWM test from P30 to P35. (b) In vitro: after 5-day culture, primary neurons were incubated with DMSO or $20 \mu \mathrm{M}$ resveratrol followed by 6-hour exposure to control gas or $4 \%$ sevoflurane.

$\mathrm{O}_{2}, 5 \% \mathrm{CO}_{2}$, and $70 \%$ nitrous oxide) exposure for $6 \mathrm{~h}$ (Figure 1(b)).

2.4. Neuron Lysis and Protein Quantification. The cells were harvested at the end of the experiments, and neuronal pellets were detergent-extracted on ice using RIPA lysis buffer (150 mM sodium chloride, Triton X-100, 0.5\% sodium deoxycholate, $0.10 \%$ sodium dodecyl sulfate, and $50 \mathrm{mM}$ Tris, $\mathrm{pH} 8.0$ ) plus $1 \mathrm{mM}$ PMSF, protease inhibitors (Promoter, Wuhan, China), and phosphatase inhibitors (Boster, Wuhan, China). The lysates were collected and centrifuged at $12,000 \mathrm{rpm}$ for $10 \mathrm{~min}$, and total protein was quantified with a BCA assay kit (Boster).

2.5. Reverse Transcriptase Polymerase Chain Reaction (RT$P C R$ ). Total RNA was extracted from hippocampal tissues with a TRIzol reagent (Invitrogen Life Technologies, Carlsbad, CA, USA) according to the manufacturer's instructions. Isolated RNA $(5 \mu \mathrm{g})$ was reverse transcribed into cDNA with an RT-PCR kit (TOYOBO, Osaka, Japan). Real-time RTPCR was carried out as follows: initial denaturation for $1 \mathrm{~min}$ at $95^{\circ} \mathrm{C}$ followed by 40 cycles of $15 \mathrm{~s}$ at $95^{\circ} \mathrm{C}, 20 \mathrm{~s}$ at $58^{\circ} \mathrm{C}$, and $45 \mathrm{~s}$ at $72^{\circ} \mathrm{C}$. The PCR primers were as follows: Sirt1 forward ( $5^{\prime}$-ATCGTTACATATTCCACGGTGCT- $\left.3^{\prime}\right)$, Sirt1 reverse $\left(5^{\prime}\right.$-CACTTTCATCTTCCAAGGGTTCT- $\left.3^{\prime}\right)$; BDNF forward ( $5^{\prime}$-GCCTCCTCTACTCTTTCTG- $\left.3^{\prime}\right)$, BDNF reverse $\left(5^{\prime}\right.$-GGATTACACTTGGTCTCGT- $\left.3^{\prime}\right)$. The intensities of the bands were analysed with Image-Pro Plus 6.0 software.

2.6. Western Blot Analysis. The harvested brain tissues and cells were subjected to western blotting as described by Narasimhan et al. [44]. In brief, hippocampal tissue lysates (40 $\mu \mathrm{g}$ protein) and primary neuron lysates $(20 \mu \mathrm{g}$ protein) were separated by SDS-PAGE on $10 \%$ polyacrylamide gels and transferred to polyvinylidene difluoride membranes. The membranes were incubated with specific primary antibodies, and the antibodies used were SIRT1 (1:500, Affinity, OH, USA), BDNF (1:500, Affinity, OH, USA), acetyl-MeCP2 (AcMeCP2) (1:1000, Millipore, Bedford, MA, USA), MeCP2 (1:1000, Cell Signaling Technology, Beverly, MA), phosphorylated CREB (p-CREB) (1:1000, ABclonal, Wuhan, China), CREB (1:500, Cell Signaling Technology, Beverly, MA), synapsin 1 (1:5000, Abcam, Cambridge, UK), VGluT1 (1:500, Abcam, Cambridge, UK), postsynaptic density 95 (PSD95) (1:500, Abcam, Cambridge, UK), and Homer1a ( $1: 2000$, Abcam, Cambridge, UK). To verify the uniformity of the protein loading and transfer efficiency across the test samples, the membranes were reprobed with GAPDH. Immunoreactive bands were developed with Immobilon Western Chemiluminescent HRP Substrate (Boster), visualized by using an enhanced chemiluminescence system (ChemiDoc, Bio-Rad, USA), and normalized to GAPDH expression.

2.7. Coimmunoprecipitation. The hippocampi were dissected from neonatal rats and then homogenized in immunoprecipitation buffer with protease inhibitors and phosphatase inhibitors, and the protein concentration was adjusted to $1 \mathrm{mg} / \mathrm{mL}$. Samples $(500 \mu \mathrm{L})$ were precleared with nonspecific rabbit IgG (Sigma) followed by adsorption on protein G-Sepharose (Millipore). Immunoprecipitation was performed overnight at $4^{\circ} \mathrm{C}$ with $5 \mu \mathrm{g}$ of rabbit anti-SIRT1 (Cell Signaling Technology), anti-AcMeCP2 (Millipore), and anti-CREB1 (Cell Signaling Technology) antibodies, followed by adsorption to protein G-Sepharose. In control experiments, the antibodies were replaced with nonspecific rabbit IgG (Sigma). For western blotting, immunoprecipitates were loaded on $10 \%$ SDS-polyacrylamide gels and then transferred onto PVDF membranes. The blots were 
incubated with specific primary antibodies and then with peroxidase-conjugated species-matched secondary antibodies. The experiments were repeated in triplicate.

2.8. Open Field Test. The locomotor and exploratory activities of the animals were monitored by the open field test. The apparatus was a white box with a $50 \times 50 \mathrm{~cm}$ field surrounded by $40 \mathrm{~cm}$ high walls. The mice were placed in the middle of the box and were given $5 \mathrm{~min}$ to move freely about the apparatus. Activity in the field was measured using an automated video-tracking system (AVTAS v3.3; AniLab Software and Instruments Co., Ltd., Ningbo, China). The total distance traveled and the average speed were monitored to calculate locomotor activity. After each session, the floor and walls of the field were cleaned with $75 \%$ ethanol to eliminate olfactory cues. To avoid experimenter bias, all behavioral experiments were performed by two experimenters who were blind to the experimental protocol. In addition, the data was analysed by another experimenter who was blind to the experimental protocol.

2.9. Morris Water Maze Test. The mice ( $n=8$ per group) used for the MWM test were weaned at P22 and tested from P31 to P35. The Morris water maze (MWM) test was performed as previously described [45-47] with small modifications. As shown in Supplementary Figure 1A, the MWM test was conducted in two separate rooms: test room and computer room. In the test room, there was a round and steel pool (diameter, $120 \mathrm{~cm}$; height, $60 \mathrm{~cm}$ ), which was filled up with water. Four graphic signals were hung on the walls as visual cues for the navigation of mice in the MWM. Swimming activity of each mouse was tracked via a camera mounted overhead and was analysed by AVTAS v3.3, an automated video-tracking system. Four platforms (platforms (1), (2), (3), and (4)) and four quadrants (quadrants 5, 6, 7, and 8) were generated automatically by the system, and platform (2) and quadrant 6 were defined as the target platform and target quadrant (Supplementary Figures 1C and 1D). The data was recorded automatically in a computer, which contains this system and was put in the computer room. By adding powdered milk, the water was rendered opaque. A platform (diametric distance, $10 \mathrm{~cm}$ ) was placed in the target quadrant (platform (2) in quadrant 6) and was $1.0 \mathrm{~cm}$ lower than the water level (Supplementary Figures $1 \mathrm{~B}$ and 1C). All mice received 5-day training followed by a probe trial. In the training days, the mice were trained to swim to a hidden platform in four trials per day for 5 days (P31P35). They are allowed to find the platform within $60 \mathrm{~s}$ and then have a 15-second stay in the platform. If a mouse failed to find the platform within $60 \mathrm{~s}$, it was guided to the platform and allowed to stay there for $15 \mathrm{~s}$. The mice were tested individually and placed into various quadrants of the pool. The daily order of entry into individual quadrants is randomized, and the mice were allowed to rest at least $30 \mathrm{~min}$ before starting the training in the other quadrants. Two hours after the end of the training trials on the fifth day, the probe trial was performed in which the platform is removed from the pool to measure spatial bias. The time spent in searching and mounting the hidden platform in the training trial (escape latency), the distance traversed to reach the hidden platform in the training trial (escape path length), the duration of time spent in each quadrant, and the number of platform crossings in the probe trial were used to assess spatial learning and memory of different group mice. To avoid experimenter bias, all behavioral experiments were performed by two experimenters who were blind to the experimental protocol. In addition, the data was analysed by another experimenter who was blind to the experimental protocol.

2.10. Statistics. The data obtained from the biochemistry studies and behavioral tests were presented as the mean \pm SEM and were analysed with GraphPad Prism 7.0 (GraphPad Software, CA, USA). Student's $t$-test was used to compare the differences between the control and sevoflurane anesthesia groups. Two-way repeated-measured analysis of variance (ANOVA) was used to evaluate the differences in escape latency and escape path length in the MWM test. Two-way ANOVA followed by the Bonferroni post hoc test was used to evaluate the interaction of groups (control vs. anesthesia) and treatments (resveratrol vs. vehicle) on the amounts of SIRT1, BDNF, p-CREB, CREB, AcMeCP2, MeCP2, synapsin1, VGluT1, PSD95, and Homer1a. The data of escape latency and escape path length obtained from the acquisition training (P31-P35) of the MWM were analysed using a twoway ANOVA (treatment $\times$ trial time) with repeated measures (trial days) followed by a Bonferroni post hoc test. The data of time spent in the target quadrant and platform crossing times obtained from probe trial (P35) were analysed using two-way ANOVA (group $\times$ treatment) without repeated measures followed by a Bonferroni post hoc test to determine significant differences between experimental groups. $P$ value $<0.05$ was considered statistically significant.

\section{Results}

3.1. Sevoflurane Exposure Inhibited SIRT1 Expression and Decreased BDNF Expression Ex Vivo and In Vitro. In the ex vivo experiment, 6-day-old mice received anesthesia with $3 \%$ sevoflurane $2 \mathrm{~h}$ daily for 3 days. The mice were sacrificed $1 \mathrm{~h}$ after anesthesia, and their hippocampi were harvested. The effects of repeated sevoflurane exposure on SIRT1 and BDNF levels were determined at the mRNA and protein levels. As shown in Figures 2(a) and 2(b), although there was no difference in the expression level of SIRT1 mRNA, BDNF mRNA expression decreased after repeated sevoflurane exposure $(P<0.01)$. At the protein level, both SIRT1 and BDNF expressions were suppressed $(P<0.01$ and $P<$ 0.05 , respectively) (Figures 2(c) $-2(\mathrm{e})$ ).

In the in vitro experiment, the neurons were treated with $4.1 \%$ sevoflurane for $6 \mathrm{~h}$ on the seventh day of culture. The neurons were lysed to detect SIRT1 and BDNF protein levels by western blotting. As shown in Figures 2(f)-2(h), the sevoflurane anesthesia reduced the protein level of SIRT1 and BDNF protein as compared to the control conditions $(P<0.01)$.

3.2. MeCP2 and CREB Expression Changed after Sevoflurane Exposure Ex Vivo and In Vitro. In hippocampus of young 


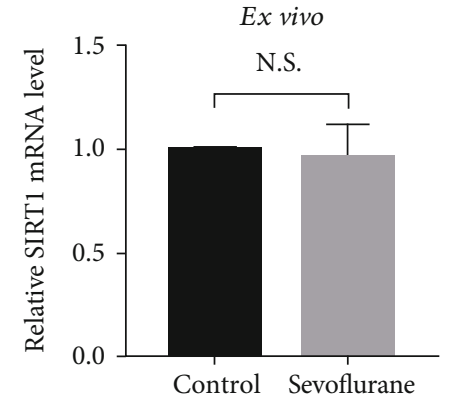

(a)

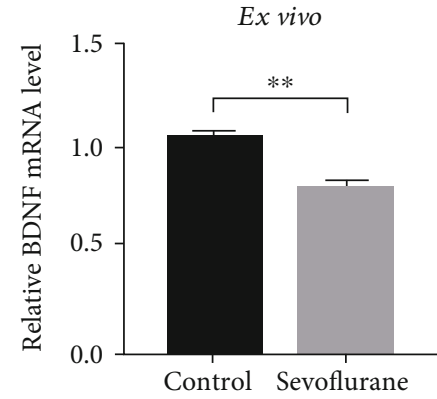

(b)

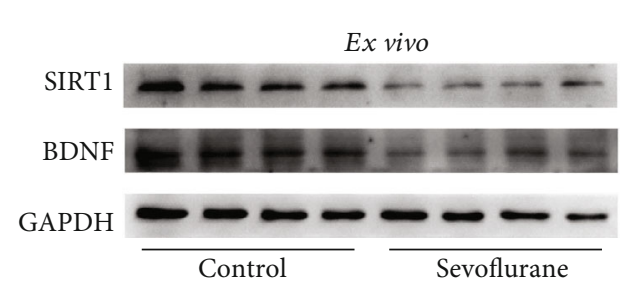

(c)

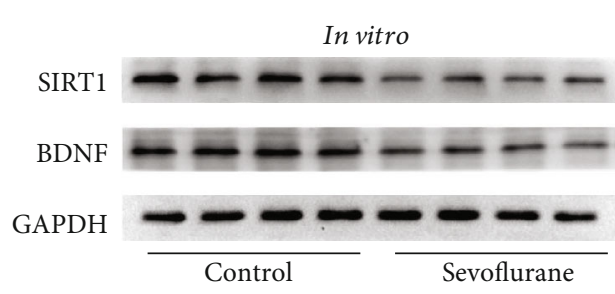

(f)

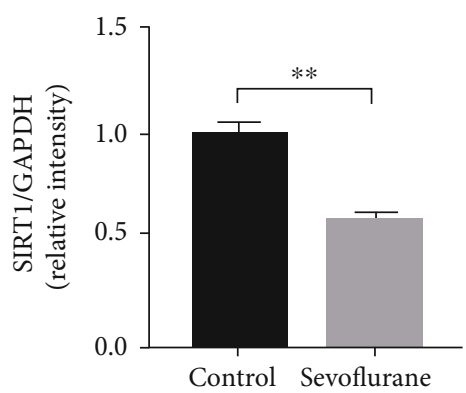

(d)

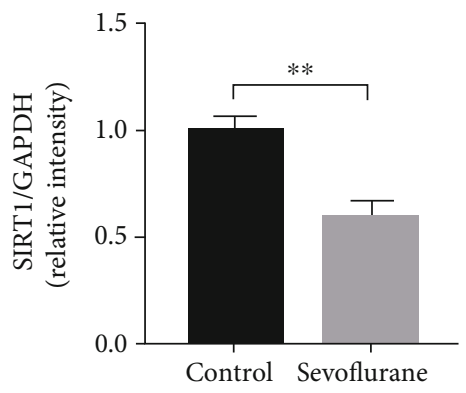

(g)

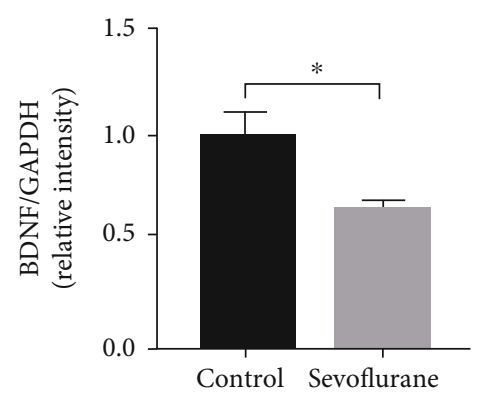

(e)

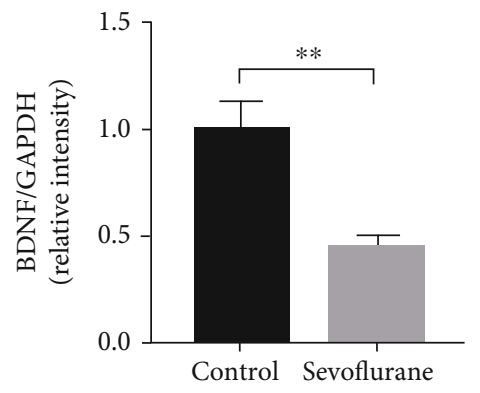

(h)

FIGURE 2: Effect of sevoflurane exposure on the expression of SIRT1 and BDNF in vivo and in vitro. (a, b) RT-PCR analysis of SIRT1 and BDNF mRNA expression between the control group and the sevoflurane group in hippocampal tissue, respectively ( $n=3$ per group). (c) Representative western blot bands of SIRT1 and BDNF in the neonatal mouse hippocampus $(n=4$ per group). (d, e) Densitometry quantification of SIRT1 and BDNF expression ex vivo, respectively. (f) Representative western blot bands of SIRT1 and BDNF in primary hippocampal neurons ( $n=4$ per group). (g, h) Densitometry quantification of SIRT1 and BDNF expression in vitro, respectively. Data are shown as means \pm SEM ( $n=4$ per group). ${ }^{*} P<0.05,{ }^{* *} P<0.01$.

mice, the expression of AcMeCP2 as well as that of total MeCP2 was increased $(P<0.05)$ (Figures 3(a)-3(c)) after sevoflurane exposure. There was no significant difference in terms of total CREB expression in hippocampal tissues between the sevoflurane anesthesia and control conditions, while the level of phosphorylated CREB (p-CREB) was declined after repeated sevoflurane exposure $(P<0.05)$ (Figures 3(a), 3(d), and 3(e)).

The quantification of the western blotting results also showed that there was a significant interaction among $\mathrm{MeCP} 2$, CREB expression, and sevoflurane exposure in primary neurons. By comparison with the control condition, the sevoflurane anesthesia group displayed significantly elevated levels of AcMeCP2 and total MeCP2 $(P<0.05)$ (Figures 3(f)-3(h)). In line with in vivo experiment, sevoflurane exposure also significantly reduced levels of phosphory- lated CREB $(P<0.05)$ without the change of total CREB expression (Figures 3(f), 3(i), and 3(j)).

\subsection{Resveratrol Prevented Sevoflurane-Induced Decreases in} SIRT1 and BDNF Expression Ex Vivo and In Vitro. Evidence has shown that resveratrol, a potent SIRT1 activator, is a powerful neuroprotective agent and may play a role in the treatment of neurodegenerative diseases [48]. Based on previous studies [37, 38, 49], three concentrations of resveratrol $(50 \mathrm{mg} / \mathrm{kg}, 100 \mathrm{mg} / \mathrm{kg}$, and $150 \mathrm{mg} / \mathrm{kg})$ were used, and the minimum effective concentration was determined for subsequent experiments. Mice were pretreated with resveratrol via intraperitoneal injection daily from $\mathrm{P} 3$ to $\mathrm{P} 6$ and $1 \mathrm{~h}$ before sevoflurane exposure on P6, P7, and P8. As shown in Figure 4(a), SIRT1 expression was upregulated dosedependently in resveratrol-treated mice in comparison with 


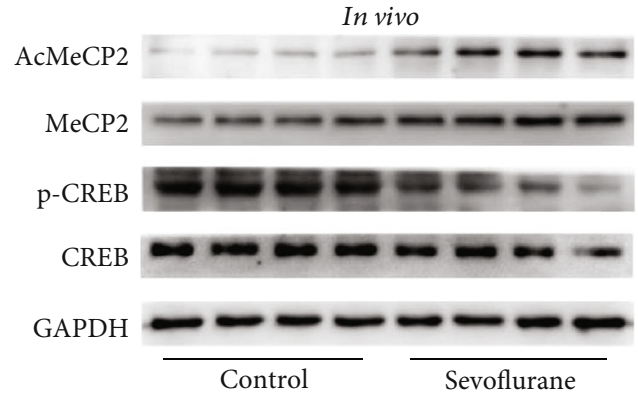

(a)

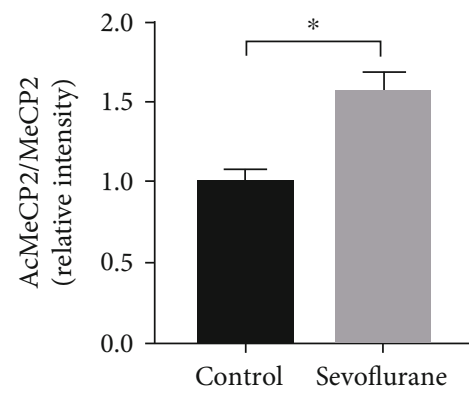

(b)

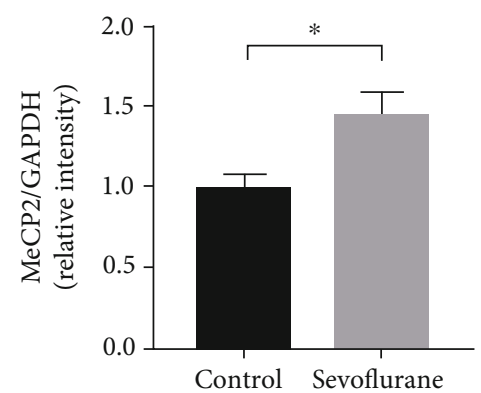

(c)

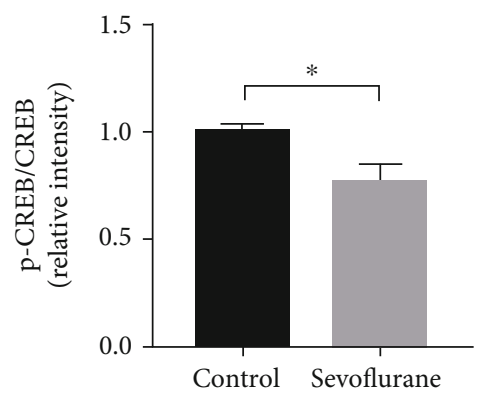

(d)

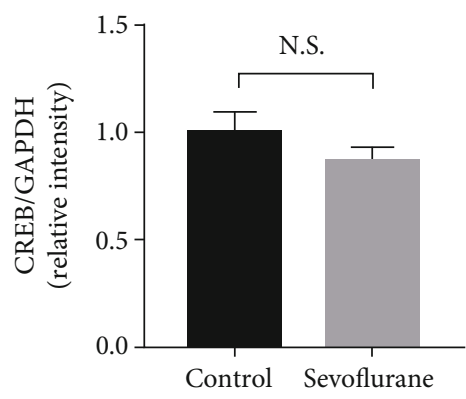

(e)

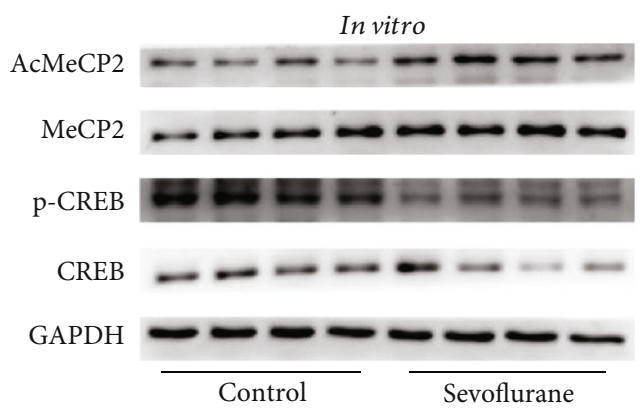

(f)

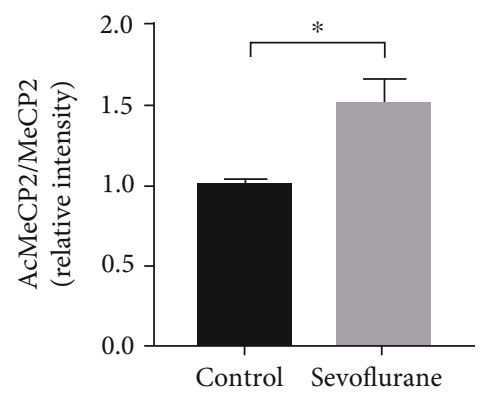

(g)

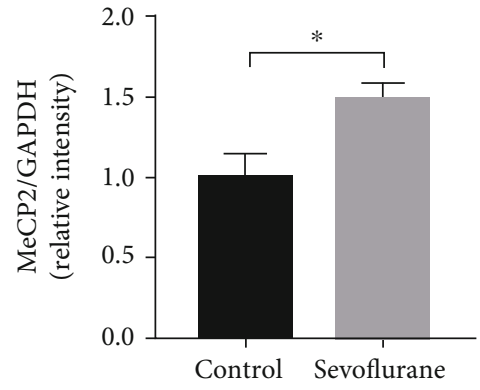

(h)

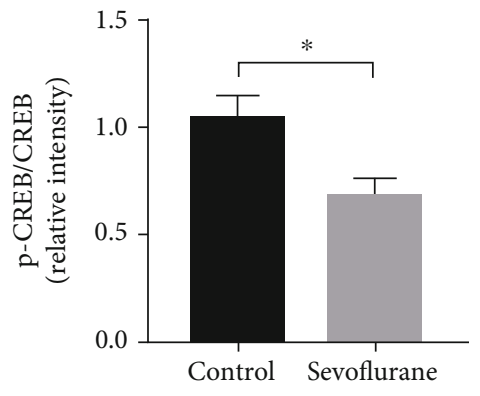

(i)

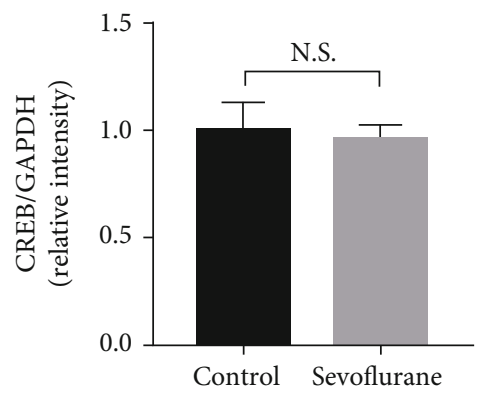

(j)

Figure 3: Alterations in MeCP2 and CREB expression. (a) Representative western blot bands of AcMeCP2, total MeCP2, p-CREB, and total CREB in the developing mouse hippocampus. (b-e) Densitometry quantification of AcMeCP2, total MeCP2, p-CREB, and total CREB expression ex vivo, respectively. (f) Representative western blot bands of AcMeCP2, total MeCP2, p-CREB, and total CREB in primary hippocampal neurons. (g-j) Densitometry quantification of AcMeCP2, total MeCP2, p-CREB, and total CREB expression in vitro, respectively. Data are shown as means \pm SEM ( $n=4$ per group). ${ }^{*} P<0.05$.

that in mice that underwent sevoflurane exposure without resveratrol pretreatment. Although the injection of $50 \mathrm{mg} / \mathrm{kg}$ resveratrol did not significantly alter SIRT1 expression, $100 \mathrm{mg} / \mathrm{kg}$ and $150 \mathrm{mg} / \mathrm{kg}$ resveratrol injection increased SIRT1 expression compared with that in the sevoflurane group $(P<0.01$ and $P<0.001)$. Thus, we chose $100 \mathrm{mg} / \mathrm{kg}$ resveratrol as the dose for the intervention experiment.

There was no difference in the expression of SIRT1 at the RNA level between mice pretreated with resveratrol or DMSO before sevoflurane exposure (Figure 4(c)). However, 


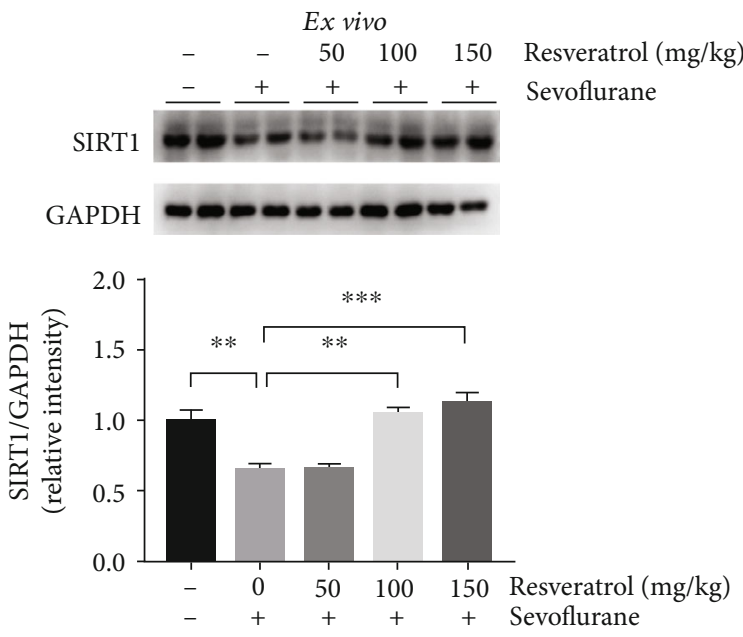

(a)

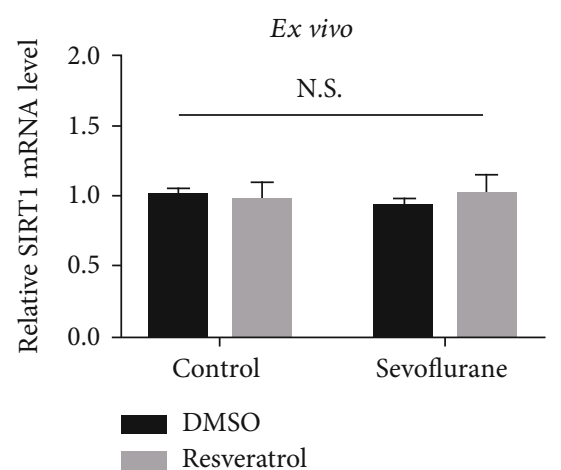

(c)

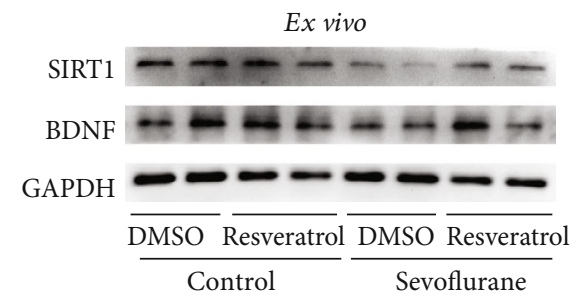

(e)

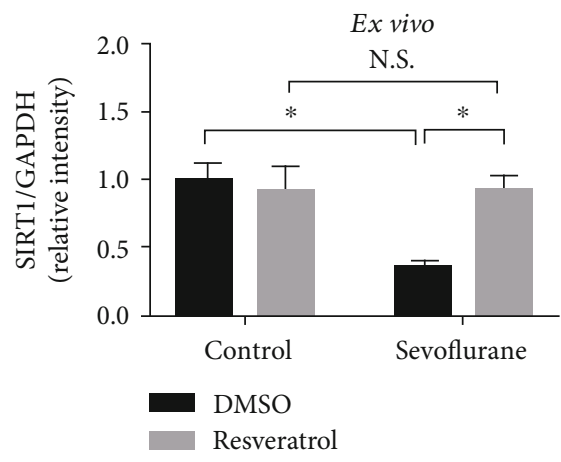

(g)

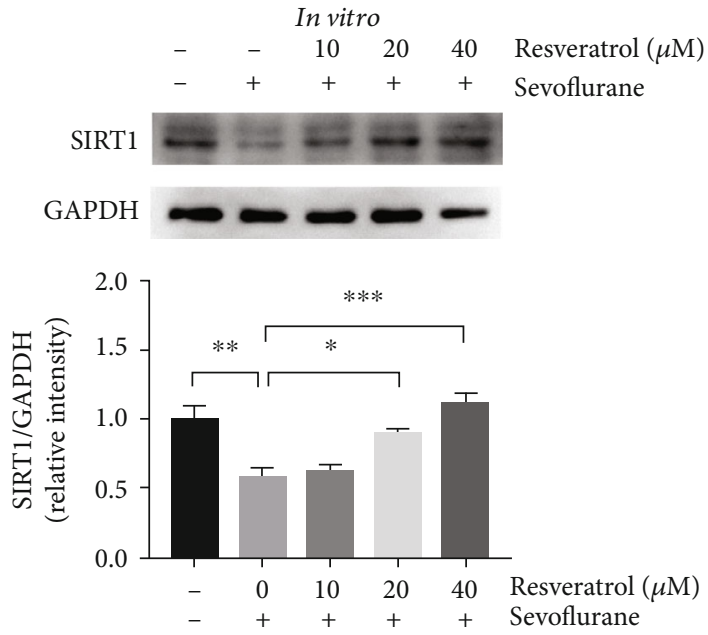

(b)

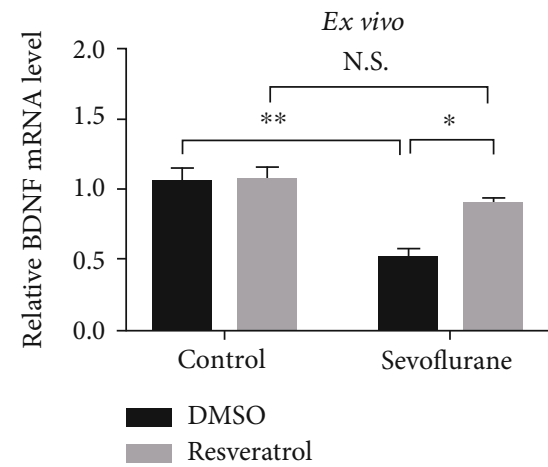

(d)

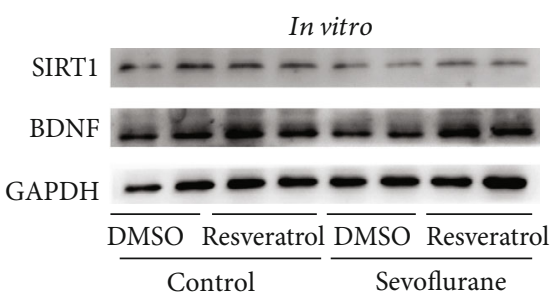

(f)

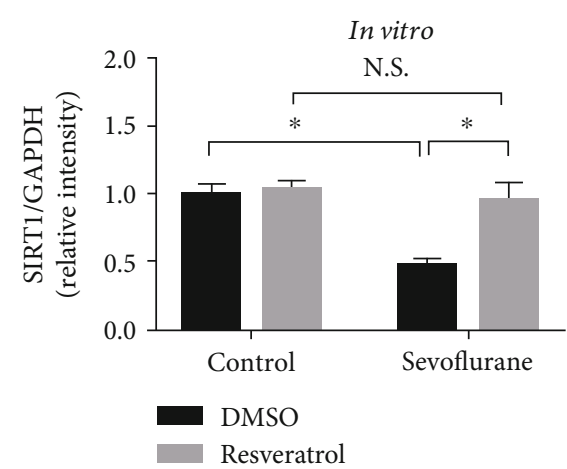

(h)

Figure 4: Continued. 


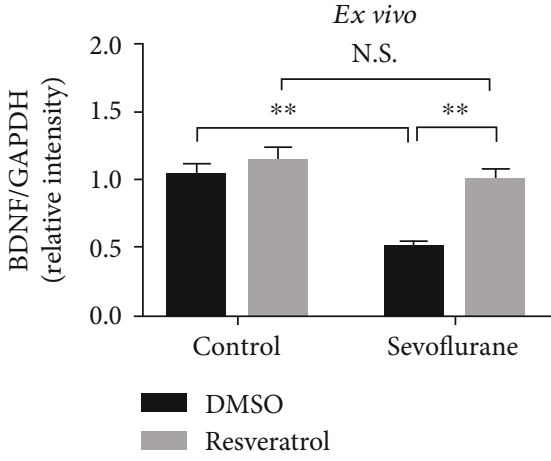

(i)

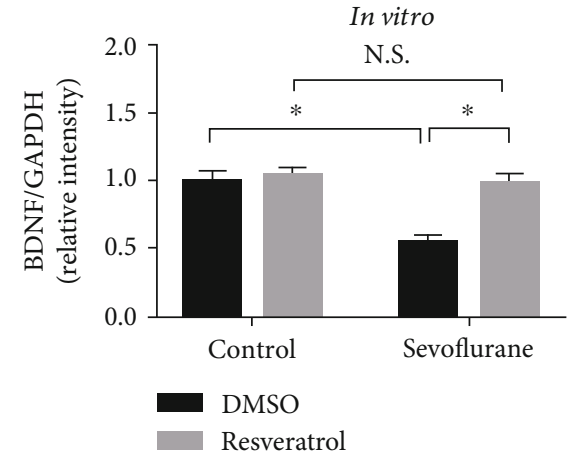

(j)

FIGURE 4: Resveratrol prevented sevoflurane-induced decreases in SIRT1 and BDNF ex vivo and in vitro. (a) Neonatal mice were pretreated with $50 \mathrm{mg} / \mathrm{kg}, 100 \mathrm{mg} / \mathrm{kg}$, and $150 \mathrm{mg} / \mathrm{kg}$ resveratrol from P3 to P8 and exposed to sevoflurane from P6 to P8. Western blotting was performed to determine the minimum effective dose of resveratrol. (b) Primary hippocampal neurons were pretreated with $10 \mu \mathrm{M}, 20 \mu \mathrm{M}$, and $40 \mu \mathrm{M}$ resveratrol $24 \mathrm{~h}$ before exposure to sevoflurane. Western blotting was used to determine the minimum effective concentration of resveratrol. (c, d) RT-PCR results showing SIRT1 and BDNF mRNA expression in the developing mouse hippocampus between groups (control group vs. sevoflurane group) and treatments (DMSO or resveratrol), respectively. (e) Representative western blot bands of SIRT1 and BDNF in the developing mouse hippocampus between groups (control group vs. sevoflurane group) and treatments (DMSO or resveratrol). (f) Representative western blot bands of SIRT1 and BDNF in hippocampal neurons between groups (control group vs. sevoflurane group) and treatments (DMSO or resveratrol). (g, i) Densitometry quantification of SIRT1 and BDNF ex vivo, respectively. $(h, j)$ Densitometry quantification of SIRT1 and BDNF protein expression in vitro, respectively. Data are shown as means \pm SEM $(n=4$ per group). ${ }^{*} P<0.05,{ }^{* *} P<0.01$, and ${ }^{* * *} P<0.001$.

BDNF expression in mice pretreated with resveratrol was elevated when compared to mice pretreated with DMSO before sevoflurane exposure $\left(F_{\text {sevoflurane }(1,12)}=22.41, P=\right.$ $0.0015 ; F_{\text {resveratrol }(1,12)}=7.015, P=0.0293$; and $F_{\text {sevoflurane* }}$ resveratrol $(1,12)=6.531, P=0.0339)$ (Figure $4(\mathrm{~d})$ ). At the protein level, sevoflurane decreased SIRT1 and BDNF expression in the mice pretreated with DMSO as compared to control conditions. However, in the mice pretreated with resveratrol, sevoflurane did not decrease the expression of SIRT1 $\left(F_{\text {sevoflurane }(1,12)}=7.066, P=0.0209 ; F_{\text {resveratrol }(1,12)}=\right.$ 4.419, $P=0.0573$; and $F_{\text {sevoflurane } * \text { resveratrol }(1,12)}=7.494, P=$ $0.018)$ and $\operatorname{BDNF}\left(F_{\text {sevoflurane }(1,12)}=16.41, \quad P=0.0016\right.$; $F_{\text {resveratrol }(1,12)}=13.59, P=0.0031 ; F_{\text {sevoflurane } * \text { resveratrol }(1,12)}=$ 5.545, $P=0.0364)$ as compared to control conditions (Figures 4(e), 4(g), and 4(i)).

Based on previous studies [50-52], hippocampal neurons were treated with resveratrol for $24 \mathrm{~h}$, and the optimal concentration of resveratrol was selected from $10 \mu \mathrm{M}, 20 \mu \mathrm{M}$, and $40 \mu \mathrm{M}$. As shown in Figure 3(b), exposure to low concentrations of resveratrol $(10 \mu \mathrm{M})$ did not prevent sevofluraneinduced SIRT1 suppression. In comparison, exposure to high concentrations of resveratrol $(20 \mu \mathrm{M}$ and $40 \mu \mathrm{M})$ for $24 \mathrm{~h}$ effectively increased SIRT1 expression $(P<0.05$ and $P<$ 0.001). Therefore, intervention group neurons were treated with $20 \mu \mathrm{M}$ resveratrol for $24 \mathrm{~h}$ before sevoflurane anesthesia. In keeping with ex vivo experiment, sevoflurane reduced SIRT1 and BDNF levels as compared to the control conditions, and resveratrol blocked the sevoflurane-induced changes in SIRT1 and BDNF levels $\left(F_{\text {sevoflurane }(1,12)}=12.76\right.$, $P=0.0038 ; \quad F_{\text {resveratrol }(1,12)}=9.084, \quad P=0.0108 ; \quad F_{\text {sevoflurane* }}$ resveratrol $(1,12)=6.665, P=0.024 ; F_{\text {sevoflurane }(1,12)}=8.63, P=$ $0.0124 ; \quad F_{\text {resveratrol }(1,12)}=7.61, \quad P=0.0173 ;$ and $F_{\text {sevoflurane* }}$ resveratrol $(1,12)=5.17, P=0.0422$, respectively) (Figures 4(f), $4(\mathrm{~h})$, and $4(\mathrm{j}))$.

3.4. Resveratrol Reversed the Expression Change of MeCP2 and CREB Induced by Sevoflurane Exposure Ex Vivo and In Vitro. Previous studies have indicated that SIRT1 could interact with AcMeCP2 and CREB [33, 53]. This finding was also confirmed by our Co-IP results (Figure 5(a)). In the ex vivo experiment, resveratrol reversed sevofluraneinduced changes in the expression of MeCP2 and CREB. Notably, following resveratrol administration, AcMeCP2 $\left(F_{\text {sevoflurane }(1,12)}=4.771, \quad P=0.0495 ; \quad F_{\text {resveratrol }(1,12)}=7.552\right.$, $P=0.0177$; and $\left.F_{\text {sevoflurane } * \text { resveratrol }(1,12)}=6.603, P=0.0246\right)$ and total MeCP2 $\left(F_{\text {sevoflurane }(1,12)}=13.08, \quad P=0.0035\right.$; $F_{\text {resveratrol }(1,12)}=8.213, P=0.0142 ;$ and $F_{\text {sevoflurane*resveratrol }}$ $(1,12)=7.521, P=0.0179)$ levels decreased, whereas the $\mathrm{p}$ CREB $\left(F_{\text {sevoflurane }(1,12)}=5.889, P=0.0319 ; F_{\text {resveratrol }(1,12)}=\right.$ 5.787, $P=0.0332$; and $F_{\text {sevoflurane*resveratrol }(1,12)}=9.886, P=$ 0.0085 ) level increased (Figures 5(b), 5(d), and 5(f)). In contrast, the CREB level was not affected by resveratrol administration (Figures 5(b), 5(h), and 5(j)).

Consistently, neurons pretreated with $20 \mu \mathrm{M}$ resveratrol before sevoflurane exposure also showed decreased expression of AcMeCP2 $\left(F_{\text {sevoflurane }(1,12)}=5.048, P=0.0442\right.$; $F_{\text {resveratrol }(1,12)}=4.903, \quad P=0.0469 ; \quad$ and $\quad F_{\text {sevoflurane* }}$ resveratrol $(1,12)=10.24, \quad P=0.0076)$ and total MeCP2 $\left(F_{\text {sevoflurane }(1,12)}=13.08, P=0.0035 ; \quad F_{\text {resveratrol }(1,12)}=8.213\right.$, $P=0.0142 ; \quad$ and $\quad F_{\text {sevoflurane* resveratrol }(1,12)}=6.686, \quad P=$ $0.0238)$ but increased expression of p-CREB $\left(F_{\text {sevoflurane }(1,12)}=7.038, \quad P=0.0211 ; \quad F_{\text {resveratrol }(1,12)}=14.32\right.$, $P=0.0026 ; \quad$ and $\quad F_{\text {sevoflurane* } * \text { resveratrol }(1,12)}=9.537, \quad P=$ 
$0.0094)$ by comparison with that in the DMSO pretreated group (Figures 5(c), 5(e), and 5(g)). The expression of CREB did not change with the use of resveratrol (Figures 5(c), 5(i), and $5(\mathrm{k}))$.

\subsection{Resveratrol Restored Synaptic Protein Expression Ex Vivo} and In Vitro. Synaptic efficacy depends on the presynaptic and postsynaptic compartments. In particular, synapsin1, vesicular glutamate transporters (VGluT1), PSD95, and Homerla are classical markers of presynaptic and postsynaptic proteins, which play an important role in synaptic activity [54-59]. Previous research has reported that the repeated sevoflurane exposure downregulates synaptic proteins such as postsynaptic protein PSD95 in the hippocampus of developing mice $[60,61]$. In the present study, we detect the effect of sevoflurane and resveratrol on the expression of these proteins. Our results indicated that repeated sevoflurane exposure induced a marked decrease in the hippocampal protein levels of synapsin1, VGluT1, PSD95, and Homerla. However, these downregulations of synaptic proteins were reversed in the presence of resveratrol treatment (synapsin1: $\quad F_{\text {sevoflurane }(1,12)}=12.19, \quad P=0.0045$; $F_{\text {resveratrol }(1,12)}=11.01, \quad P=0.0061 ; \quad$ and $F_{\text {sevoflurane } * \text { resveratrol }(1,12)}=9.139, \quad P=0.0106 ; \quad$ VGluT1: $F_{\text {sevoflurane }(1,12)}=15.39, P=0.0020 ; F_{\text {resveratrol }(1,12)}=9.535, P$ $=0.0094 ;$ and $F_{\text {sevoflurane*resveratrol }(1,12)}=5.172, P=0.0421$; PSD95: $\quad F_{\text {sevoflurane }(1,12)}=6.935, \quad P=0.0218 ; \quad F_{\text {resveratrol }(1,12)}$ $=5.654, P=0.0349 ;$ and $F_{\text {sevoflurane*resveratrol }(1,12)}=6.887, P$ $=0.0222$; and Homerla: $F_{\text {sevoflurane }(1,12)}=16.89, P=0.0014$; $F_{\text {resveratrol }(1,12)}=8.179, \quad P=0.0144 ; \quad$ and $\left.F_{\text {sevoflurane } * \text { resveratrol }(1,12)}=5.577, P=0.0359\right)$ (Figures $6(\mathrm{a})$, 6(c), 6(e), 6(g), and 6(i)).

Consistently, long-term sevoflurane exposure in primary neurons also led to a significant decrease in the protein levels of presynaptic proteins (synapsin1 and VGluT1), along with the downregulation of postsynaptic proteins (PSD95 and Homerla) in the PSD fraction. However, these changes in synaptic proteins induced by sevoflurane were significantly attenuated by pretreatment with resveratrol (synapsin1: $F_{\text {sevoflurane }(1,12)}=8.505, \quad P=0.0129 ; \quad F_{\text {resveratrol }(1,12)}=4.853$, $P=0.0479 ;$ and $F_{\text {sevoflurane*resveratrol }(1,12)}=5.719, P=0.034$; VGluT1: $\quad F_{\text {sevoflurane }(1,12)}=7.698, P=0.0168 ; F_{\text {resveratrol }(1,12)}$ $=9.36, P=0.0099 ;$ and $F_{\text {sevoflurane } * \text { resveratrol }(1,12)}=6.711, P=$ 0.0236; $\quad$ PSD95: $\quad F_{\text {sevoflurane }(1,12)}=7.643, \quad P=0.0171$; $F_{\text {resveratrol }(1,12)}=5.108, \quad P=0.0432 ;$ and $F_{\text {sevoflurane* } * \text { resveratrol }}$ $(1,12)=5.5851, P=0.0359$; and Homer1a: $F_{\text {sevoflurane }(1,12)}=$ 9.21, $\quad P=0.0104 ; \quad F_{\text {resveratrol }(1,12)}=7.464, \quad P=0.0182 ; \quad$ and $\left.F_{\text {sevoflurane*resveratrol }(1,12)}=5.892, P=0.0319\right) \quad$ (Figures $6(\mathrm{~b})$, $6(d), 6(f)$, and $6(j))$.

3.6. Spatial Memory Deficits Induced by Early Repeated Exposure to Sevoflurane Were Alleviated by Treatment with Resveratrol. To determine the long-term cognitive effects of repeated isoflurane exposure and resveratrol treatment, the MWM test was used to detect the spatial memory of the different groups of mice on P31. Before the MWM test, the motor function of young mice was measured by the open field test. As displayed in Figures 7(a) and 7(b), the total distance traveled and average speed did not differ among the four groups of mice. In the MWM test, all groups of mice learned to locate a hidden platform, as evidenced by the decreasing escape latencies $\left(F_{\text {time }(4,112)}=9.702, P<0.001\right)$ and escape path length $\left(F_{\text {time }(4,112)}=9.503, P<0.001\right)$ over the training period, and the difference was observed between the groups during the same day $\left(F_{\text {treatment }(3,28)}=9.693, P<\right.$ $0.001 ; F_{\text {treatment }(3,28)}=4.877, P<0.01$ ) (Figure $\left.6(\mathrm{c})\right)$. A post hoc test (Bonferroni) showed that, compared with control mice, the mice exposed to sevoflurane required longer escape latency and escape path length to locate the position of the platform in the MWM pool on P34 $(P<0.01, P<0.05$, respectively) and $\mathrm{P} 35(P<0.05, P<0.05$, respectively $)$ (Figures $7(\mathrm{~d})$ and $7(\mathrm{e})$ ). The mice that were exposed to sevoflurane, compared to control mice, also spent less time in the target quadrant $\left(F_{\text {sevoflurane }(1,28)}=5.455, P=0.0269\right.$; $F_{\text {resveratrol }(1,28)}=4.97, P=0.034$; and $F_{\text {sevoflurane*resveratrol }(1,28)}$ $=4.428, P=0.0445)$ (Figure $7(\mathrm{f}))$ and crossed the platform fewer times $(P<0.05)$ (Figure $7(\mathrm{~g}))$.

On the other hand, the Bonferroni post hoc test showed that, compared with sevoflurane mice, the mice pretreated with resveratrol before sevoflurane required shorter escape latency and escape path length to locate the position of the platform in the MWM pool on P34 $(P<0.01$ and $P<0.05$, respectively) and P35 ( $P<0.05$ and $P<0.05$, respectively), longer time in the target quadrant $\left(F_{\text {sevoflurane }(1,28)}=5.455\right.$, $P=0.0269 ; F_{\text {resveratrol }(1,28)}=4.97, P=0.034$; and $F_{\text {sevoflurane* }}$ resveratrol $(1,28)=4.428, P=0.0445)$ and crossed the platform more times $(P<0.05)$ (Figures $7(\mathrm{c})-7(\mathrm{~g}))$.

\section{Discussion}

In the present study, we found that SIRT1 deficiency was associated with prolonged cognitive impairment in developing mice following repeated sevoflurane exposure. Sevofluraneinduced SIRT1 inhibition led to the inactivation of MeCP2 and CREB, two critical epigenetic regulators of BDNF, and then reduced the expression of BDNF in the hippocampus. Pretreatment with resveratrol, an agonist of SIRT1, almost restored the expression of SIRT1, increased the epigenetic regulation of $\mathrm{MeCP} 2$ and $\mathrm{CREB}$, promoted the expression of BDNF, and consequently mitigated the cognitive deficits. Collectively, our findings showed that SIRT1 deficiency modulated BDNF signaling by influencing the epigenetic activity of MeCP2 and CREB and suggested a promising method for mitigating the neurotoxicity induced by sevoflurane in developing mice.

BDNF has been shown to regulate the survival and the differentiation of neurons and dynamically modulate the synaptic plasticity in the developing brain $[23,24,34]$. BDNF deficiency in the CA1 of the hippocampus led to impaired long-term potentiation and synaptic structure, and administration of recombinant BDNF almost reversed these pathological effects [23, 62]. Several lines of evidence indicated that impaired BDNF signaling was associated with increased 


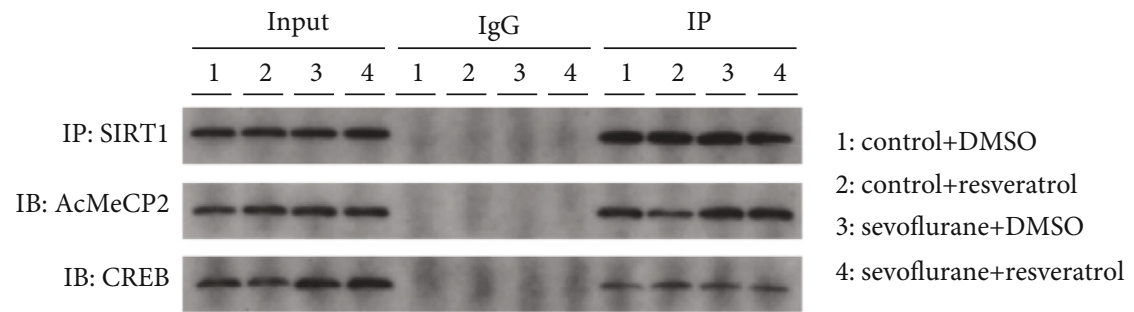

(a)

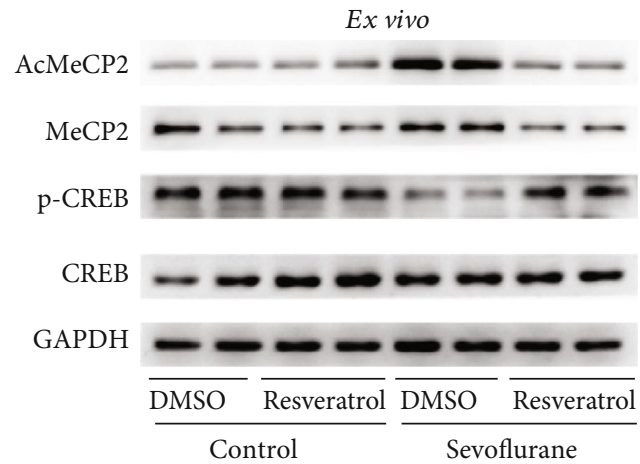

(b)

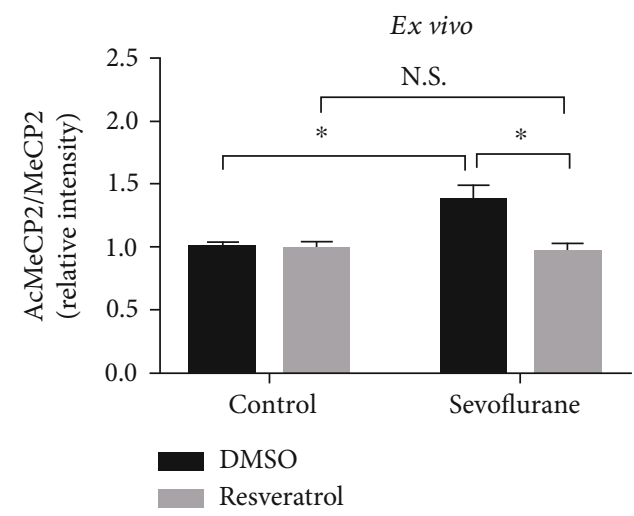

(d)

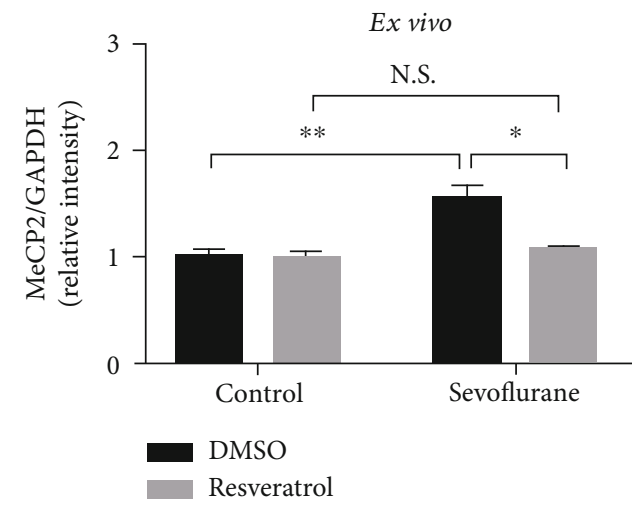

(f)

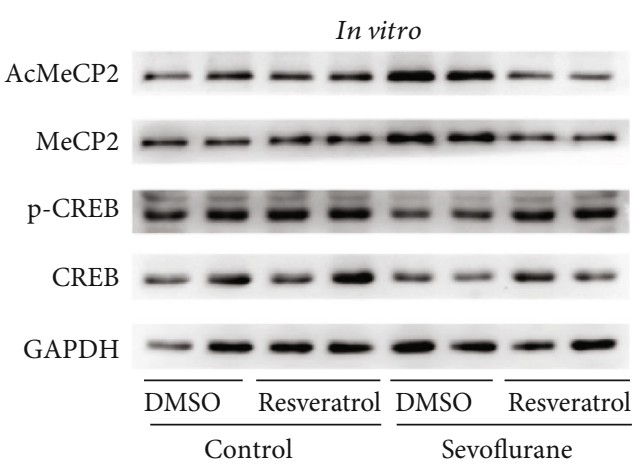

(c)

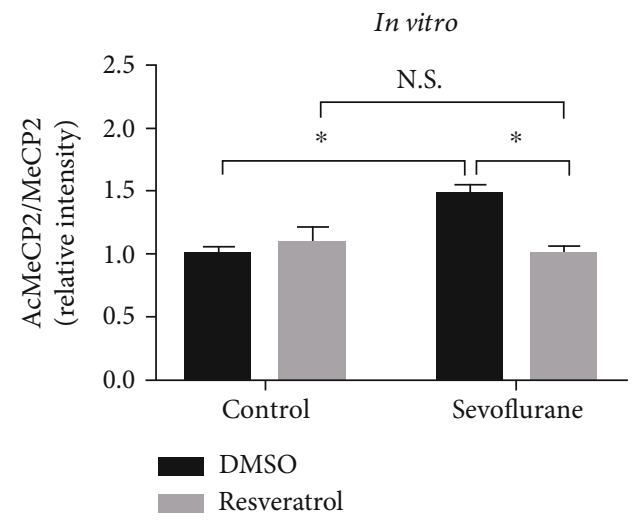

(e)

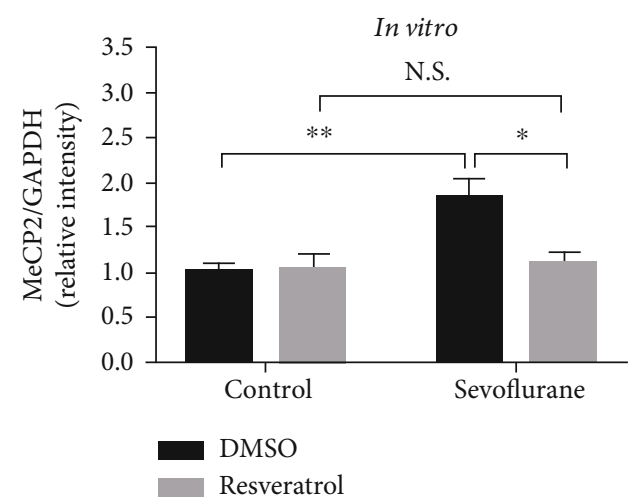

(g)

Figure 5: Continued. 


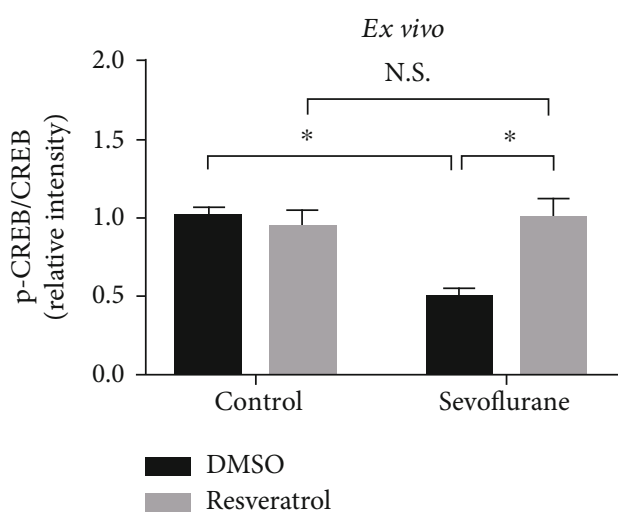

(h)

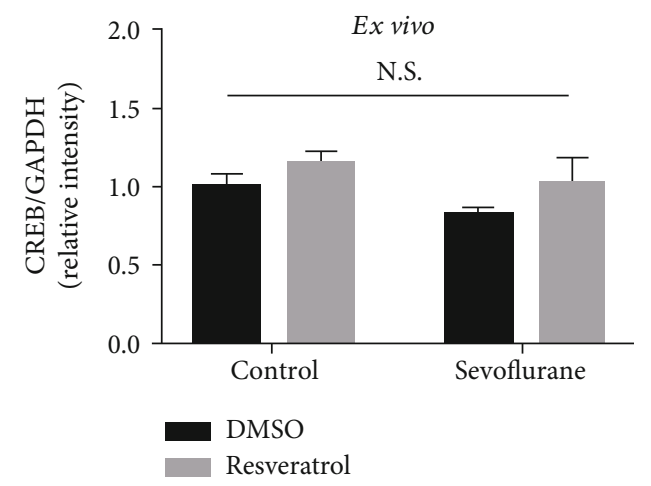

(j)

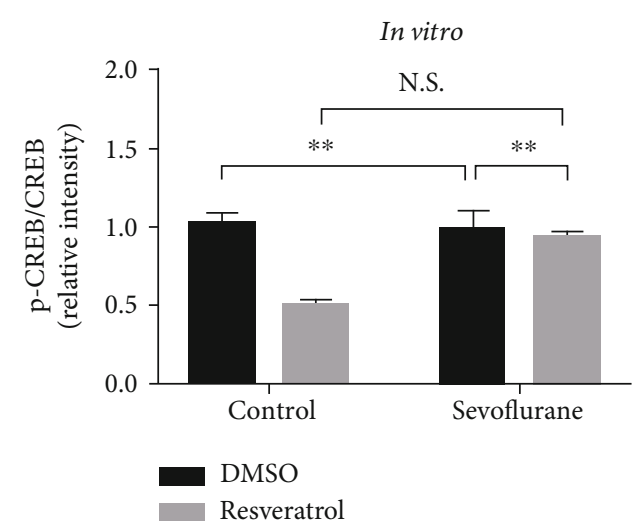

(i)

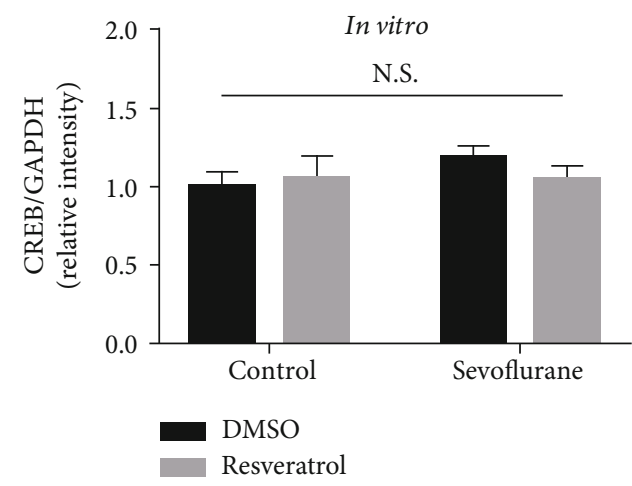

$(\mathrm{k})$

FIGURE 5: Resveratrol reversed the change in the expression of MeCP2 and CREB induced by sevoflurane exposure ex vivo and in vitro. (a) CoIP results for SIRT1, AcMeCP2, and CREB. (b) Representative western blot bands of AcMeCP2, total MeCP2, p-CREB, and total CREB in the developing mouse hippocampus between groups (control group vs. sevoflurane group) and treatments (DMSO or resveratrol). (c) Representative western blot bands of AcMeCP2, total MeCP2, p-CREB, and total CREB in primary hippocampal neurons between groups (control group vs. sevoflurane group) and treatments (DMSO or resveratrol). (d, f, h) Densitometry quantification of AcMeCP2, total $\mathrm{MeCP} 2$, p-CREB, and total CREB expression ex vivo, respectively. (e, g, i) Densitometry quantification of AcMeCP2, total MeCP2, pCREB, and total CREB expression in vitro, respectively. Data are shown as means \pm SEM ( $n=4$ per group). ${ }^{*} P<0.05,{ }^{* *} P<0.01$.

neuroapoptosis and disrupted synaptic components in the neonatal rodent following exposure to commonly used GAs [27-29, 62]. In agreement with the aforementioned findings, our data showed that sevoflurane downregulated BDNF in the hippocampi of neonatal mice. BDNF played an important role in synaptic plasticity, partially owing to the regulation of the local synthesis of proteins, including the presynaptic and postsynaptic molecules $[24,63]$. As expected, we found that sevoflurane-induced BDNF reduction resulted in decreased levels of the presynaptic components (synapsin 1 and VGluT1) and the postsynaptic component (PSD95). Surprisingly, we also found that Homerla, a key neuroprotective endogenous molecule, was downregulated by sevoflurane. As is known, Homerla belongs to the postsynaptic density family [64], but it is unknown whether the change of Homerla is related to the decrease of BDNF in the present study. In addition, the present and previous studies demonstrated that upregulated expression of BDNF mitigated GA-induced neurotoxicity in the developing brain $[30,65]$. As is known, $\mathrm{BDNF}$ can be produced in neurons, astrocytes, and microglia in the brain. Previous studies showed that neonatal exposure to isoflurane induced BDNF reduction in astrocytes and then promoted neuronal loss [66-68]. In our animal models, we only measured the gross effect of sevoflurane on the expression of BDNF in the developing brain, so we could not find the precise resource of BDNF. Taking into account the experiment of cultured neurons, we cautiously indicated that sevoflurane exposure reduced the expression of BDNF in developing neurons. However, we cannot rule out the possibility that sevoflurane may change the production of BDNF from astrocytes or microglia. These direct and indirect evidences support the notion that the inhibition of neuronal BDNF signaling contributes to the sustained neurobehavioral abnormality in experimental models with repeated exposure to GAs.

The biosynthesis of BDNF can be modulated at different levels. Recently, increasing attention has been paid to the epigenetic reprogramming of BDNF because this regulation mechanism takes part in activity-dependent synaptic function and the crosstalk of neuronal circuits [69, 70]. As aforementioned, GAs inhibited the expression of BDNF when administered at the peak of brain development, and an increasing number of studies had been conducted to explore the mechanism by which GAs regulated the expression of 
Ex vivo

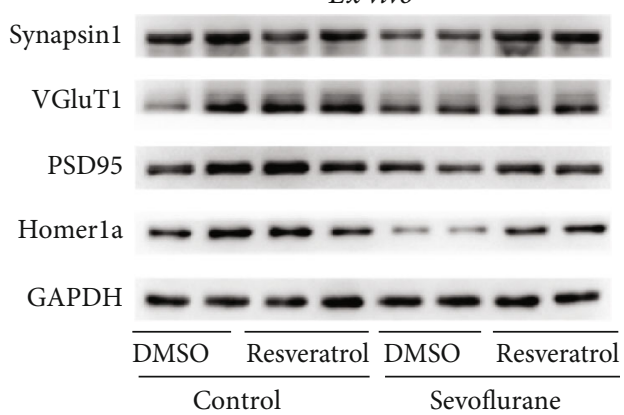

(a)

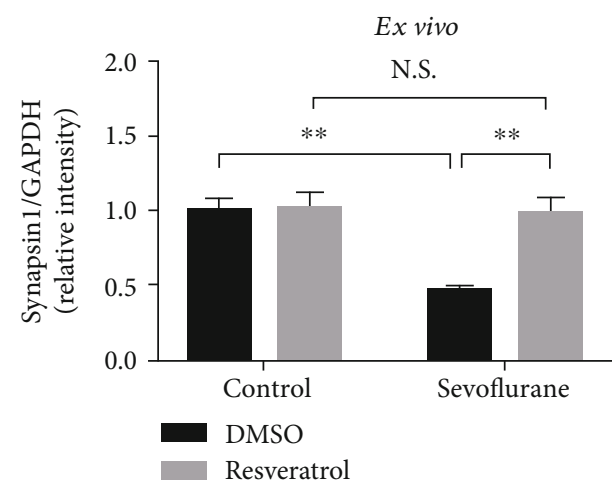

(c)

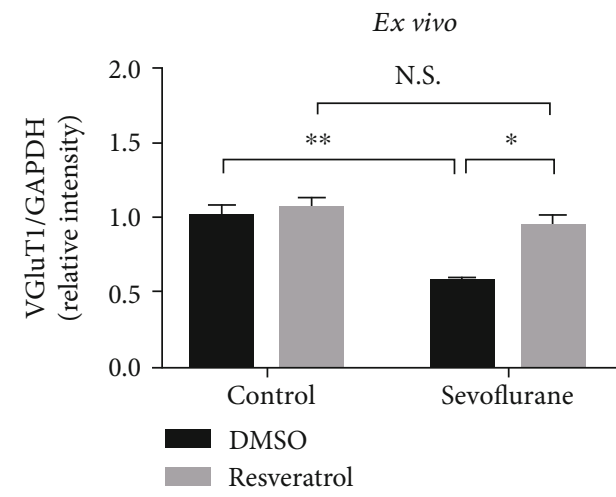

(e)

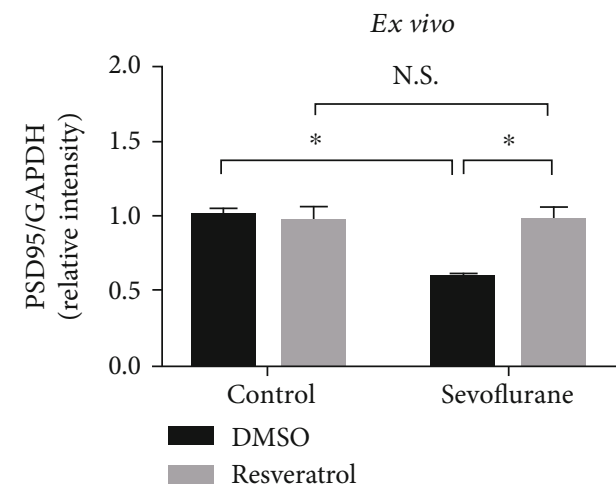

(g)
In vitro

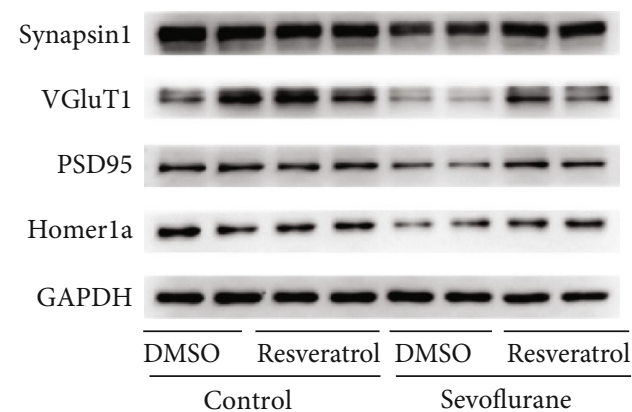

(b)

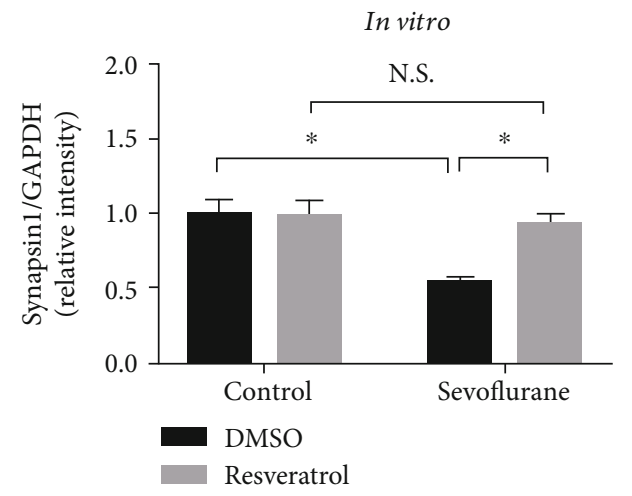

(d)

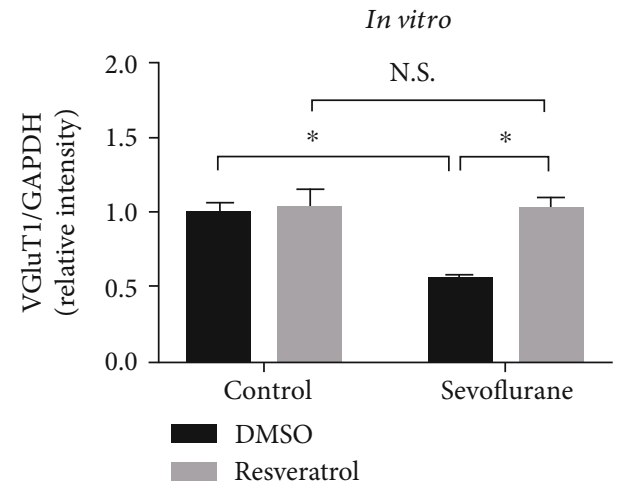

(f)

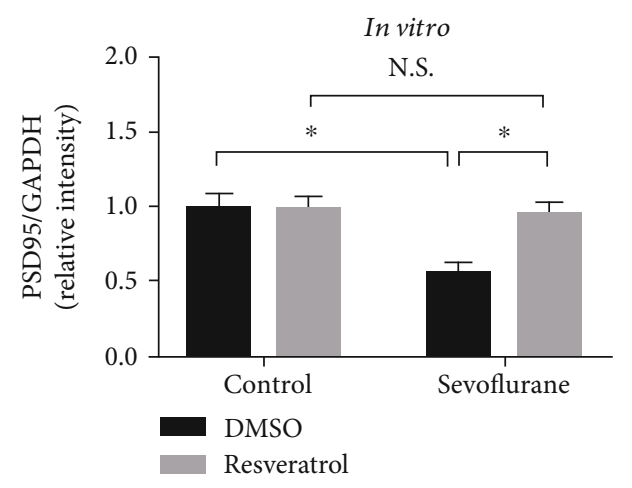

(h)

Figure 6: Continued. 


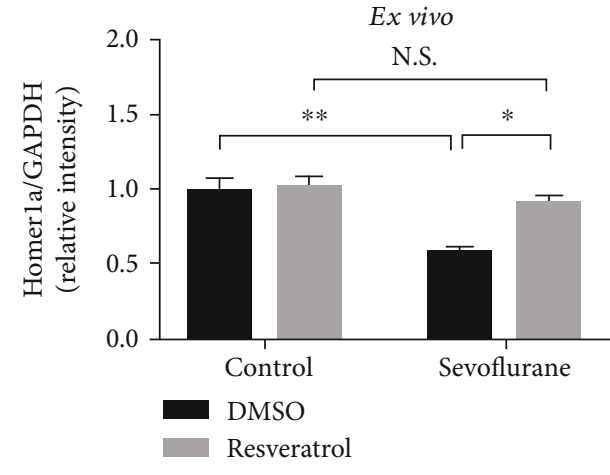

(i)

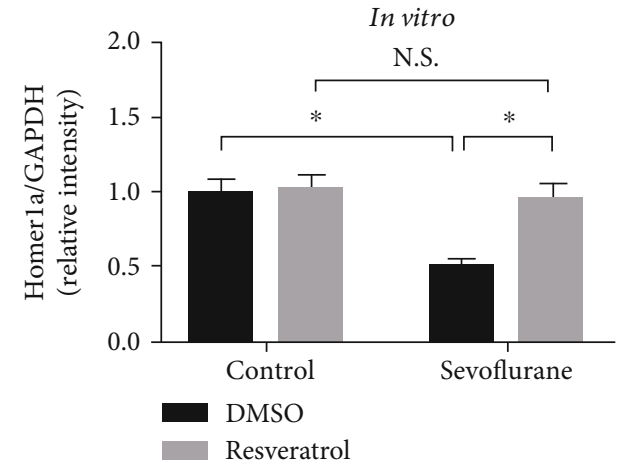

(j)

FIGURE 6: Resveratrol restored synaptic protein expression ex vivo and in vitro. (a) Representative western blot bands of synapsin1, VGluT1, PSD95, and Homerla protein in the developing mouse hippocampus between groups (control group vs. sevoflurane group) and treatments (DMSO or resveratrol). (b) Representative western blot bands of synapsin1, VGluT1, PSD95, and Homer1a protein in primary hippocampal neurons between groups (control group vs. sevoflurane group) and treatments (DMSO or resveratrol). (c, e, g, i) Densitometry quantification of synapsin1, VGluT1, PSD95, and Homer1a in vivo, respectively. (d, f, h, j) Densitometry quantification of synapsin1, VGluT1, PSD95, and Homerla in vitro, respectively. Data are shown as means \pm SEM $(n=4$ per group $) .{ }^{*} P<0.05,{ }^{* *} P<0.01$.

BDNF $[1,30,71]$. In light of the widespread use of sevoflurane in current pediatric anesthesia, we attempted to explore how sevoflurane influenced the expression of BDNF in the developing brain in the present study. We found that the level of acetylated MeCP2 is increased and the level of phosphorylated CREB is decreased in the hippocampi of developing mice following repeated exposure to sevoflurane. As is known, MeCP2 and CREB are two key transcriptional factors that regulate the expression of BDNF in the central nervous system [70]. Their abnormal activity led to BDNF reduction and then impaired the biosynthesis of synaptic proteins [69, 72] in our study. Furthermore, we found that resveratrol, an agonist of SIRT1, almost normalized the sevofluraneinduced changes of MeCP2 and CREB in the hippocampus. Indeed, we found that SIRT1 was inhibited by isoflurane, another inhalational anesthetics, in neonatal rats in our previous study [73]. Therefore, we examined the effect of sevoflurane on the expression of SIRT1 in the hippocampus and did confirm that SIRT1 was reduced by sevoflurane in the current study. It was reported that SIRT1 has been strongly implicated in normal synaptic plasticity and cognitive function $[32,53]$ by regulating the level of acetylated $\mathrm{MeCP} 2$ and the transcriptional activity of CREB in the brain $[33,34]$. However, it is unclear whether sevoflurane-induced SIRT1 inhibition modulates the expression of BDNF by inhibiting the activity of MeCP2 and CREB. Together, these findings suggest that SIRT1 reduction and inhibited activity of MeCP2 and CREB are related to sevoflurane-induced decreased BDNF in the developing hippocampus.

SIRT1, a NAD-dependent class III histone deacetylase (HDAC), is involved in various physiological and pathophysiological processes, including neurodevelopment, aging, metabolism, inflammation, and cancer [35]. Its substrates include histone proteins as well as nonhistone proteins [74]. In the present study, we hypothesized that there was a link between the SIRT1 inhibition and abnormal activity of MeCP2 and CREB in developing mice following sevoflurane exposure. To test this hypothesis, we pretreated the neonatal mice with resveratrol before sevoflurane anesthesia. We found that resveratrol pretreatment rescued SIRT1 inhibition, reduced the level of acetylated MeCP2, and increased the levels of phosphorylated CREB and BDNF in the hippocampal tissue and in cultured hippocampal neurons. Furthermore, our coimmunoprecipitation experiment confirmed that SIRT1 could directly bind to MeCP2 or CREB, respectively. CREB-binding protein (CBP) was reduced by sevoflurane in neonatal rats [65]. Similar findings were observed in another study in which general anesthesia (midazolam-nitrous oxide-isoflurane) for 6 hours resulted in CBP reduction in neonatal rats at 24 hours after the treatment ended [71]. In the present study, we found that CBP was not likely correlated with the expression of SIRT1; therefore, the data of CBP was not present. In previous neurodegenerative models, SIRT1 was involved in the regulation of miR134 and transducers of regulated CREB1 (TORC1) and influenced the expression of $\operatorname{BDNF}[33,34]$. We found that SIRT1 was involved in the regulation of the level of phosphorylated CREB but did not further investigate the potential mechanism by which SIRT1 mediated changes in the transcriptional activity of CREB to affect the expression of BDNF, which is a limitation of our study.

Given the indispensable role of BDNF in GA-induced developmental neurotoxicity, it is essential to explore feasible therapeutic methods for rescuing the expression of BDNF. Several studies found that the increased expression of some class I and class II HADCs was involved in suppressing the expression of BDNF triggered by GA exposure during early life $[30,65,71,75,76]$. Theoretically, inhibitors of HDACs might be useful. Strikingly, this hypothesis was supported by a recent study showing that MS-275, a selective inhibitor of class I histone deacetylases (HDAC2, HDAC3, and HDAC8) [77], and sodium butyrate restore GA-induced synaptic alterations along with BDNF alterations $[65,71]$. However, it has been reported that inhibitors of class I HDACs have intrinsic toxic side effects and that there is thus a small therapeutic window, which prevents their application in the 


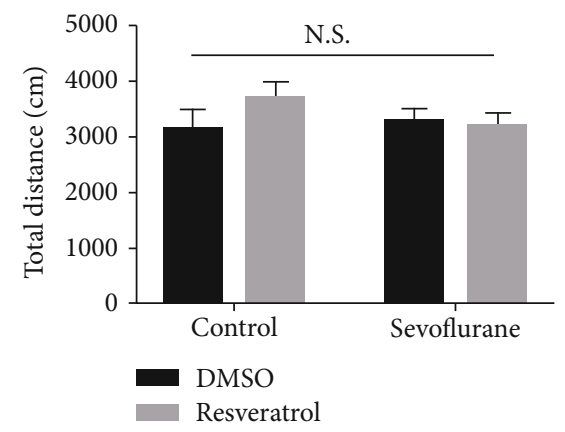

(a)
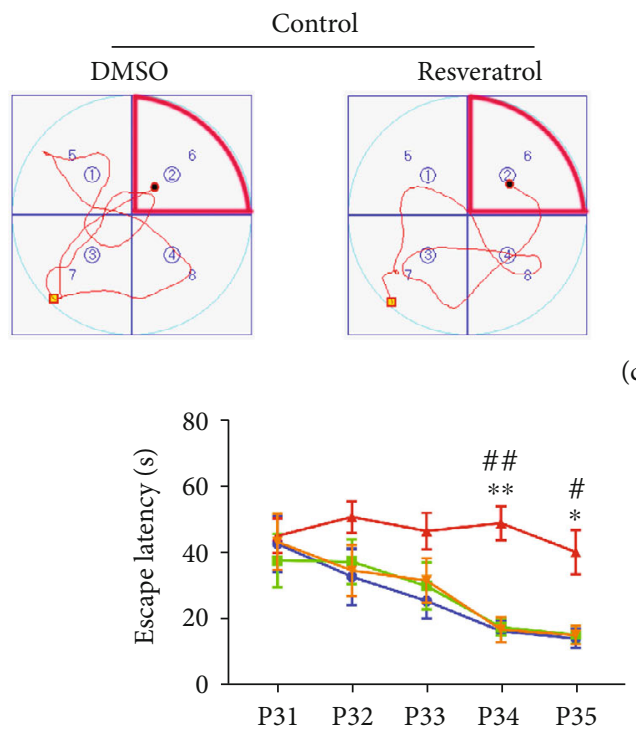

$\rightarrow$ Control+DMSO

- - Control+resveratrol

$\rightarrow$ Sevoflurane+DMSO

$\longrightarrow$ Sevoflurane+resveratrol

(d)

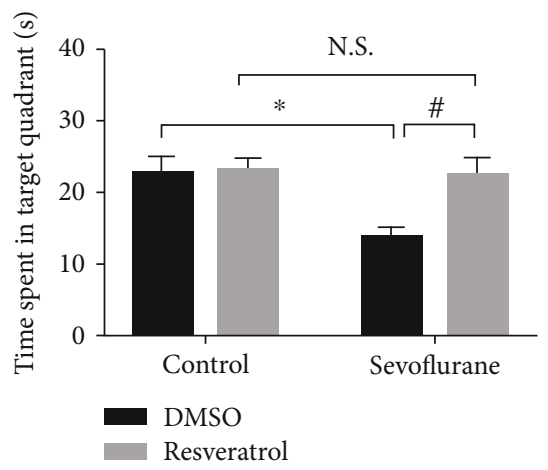

(f)

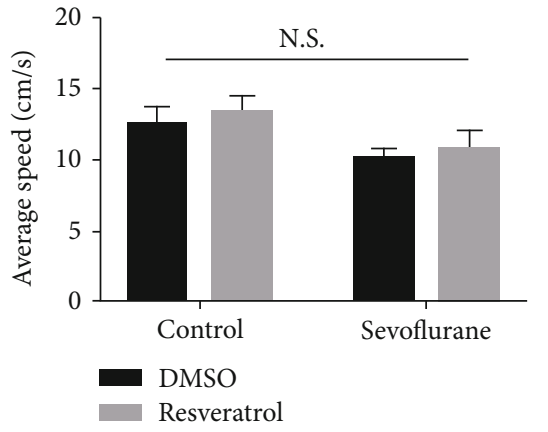

(b)

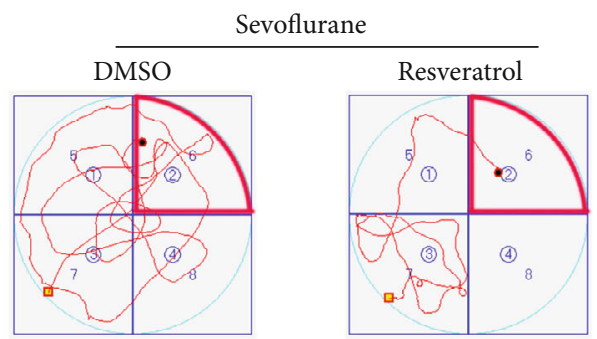

(c)

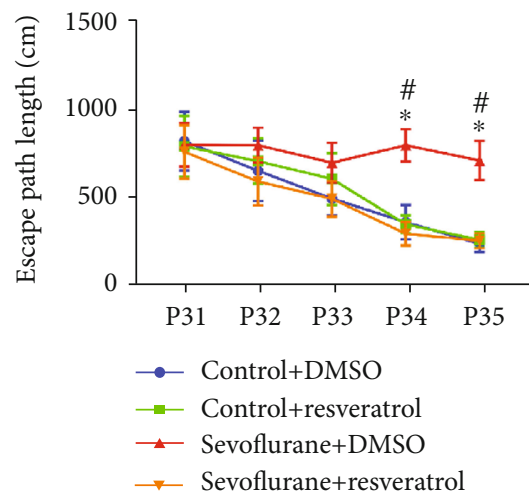

(e)

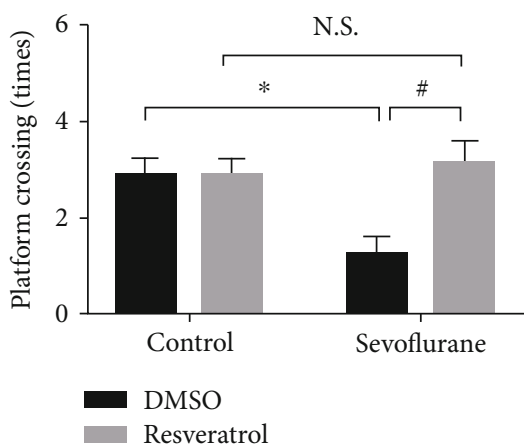

(g)

FIGURE 7: Motor function and spatial memory changes induced by sevoflurane exposure and pretreatment with resveratrol. (a) Total distance traveled by four groups of mice in the open field test. (b) The average speed traveled by four groups of mice in the open field test. (c) Representative swimming paths of the mice in the four experimental groups obtained from the training in quadrant 7 on P34. The mice were placed in the water facing the pool wall at the yellow point in quadrant 7 on the fourth day of training; the swimming path of mice was finished at the black point. Quadrant 6 is the target quadrant (marked by red lines), and platform (2) is the target platform. (d) The escape latency in the MWM plotted against the training days. (e) The escape path length in the MWM plotted against the training days. (f) Analysis of the time spent in each quadrant during the probe trial of the MWM. (g) The platform crossing times during the probe trial of the MWM test. Data are shown as means \pm SEM $\left(n=8\right.$ per group). ${ }^{*} P<0.05,{ }^{* *} P<0.01$, control+DMSO vs. sevoflurane+DMSO; ${ }^{\#} P<0.05,{ }^{\# \#} P<0.01$, sevoflurane+resveratrol vs. sevoflurane+DMSO. 
clinical setting [78]. In the present study, we found that resveratrol pretreatment almost restored the expression of SIRT1 and increased the expression of BDNF by influencing the transcriptional factors $\mathrm{MeCP} 2$ and CREB. Resveratrol $\left(3,4^{\prime}, 5\right.$-trihydroxystilbene $\left.\left(\mathrm{C}_{14} \mathrm{H}_{12} \mathrm{O}_{3}\right)\right)$ is a natural polyphenolic nutraceutical that has pleiotropic properties, including antioxidation, anti-inflammation, antiapoptosis, and anticancer properties in multiple organs under a wide variety of pathological conditions [79]. It has been reported that supplementation with resveratrol improves memory performance in association with increased hippocampal function connectivity in elderly adults [80]. Besides being known as an agonist of SIRT1, resveratrol also acts as an inhibitor of the mammalian target of rapamycin (mTOR) [81, 82]. Amounts of studies implied that resveratrol could influence autophagy, oxidative stress, and inflammation through the mTOR pathway [49, 82-84]. Additionally, the mTOR pathway was found to take part in the regulation of dendritic growth, synapse formation, and synaptic protein expression [85-87]. It was reported that general anesthetics, including sevoflurane, induced developmental neuronal injury by activating the mTOR pathway [87-90]. In light of the fact that mTOR and BDNF interact in a complicated way in physiological or pathological settings [91, 92], we did not explore the crosstalk between BDNF and mTOR signaling in the sevoflurane-induced injury in the present study. Therefore, it needs to be further investigated whether mTOR signaling is involved in the protection of resveratrol against sevoflurane-induced impairment.

To our knowledge, we have provided the first evidence that resveratrol pretreatment mitigates sevoflurane-induced developmental neurodegeneration and improves long-term cognitive function. Although the efficacy, safety, and pharmacokinetics of resveratrol have been documented in more than 200 clinical trials, there is not yet any trial on its potential to prevent GA-induced neurotoxicity. We hypothesize that resveratrol might be a promising medication for preventing the noxious effect of GA in the developing brain. Although the clinical use of resveratrol is documented in stroke and other neurodegenerative diseases, its poor bioavailability and rapid metabolism may limit its use [93, 94]. Therefore, longer-acting SIRT1 agonists more readily absorbed will be more clinically relevant.

\section{Conclusions}

Taken together, our study suggested that SIRT1 reduction was associated with sevoflurane-induced neurotoxicity. SIRT1 deficiency increases MeCP2 acetylation and decreases CREB phosphorylation, thus resulting in the downregulation of BDNF in the hippocampus of the developing brain. Also, pretreatment with resveratrol mitigates the sevoflurane-induced changes of SIRT1, MeCP2, and CREB in the hippocampus and improves the prolonged neurobehavioral performance in the developing model. Our findings proposed a new mechanism of sevoflurane-induced neurotoxicity in the developing brain and suggested that these long-term cognitive deficits could be mitigated by activating SIRT1.

\section{Data Availability}

The data used to support the findings of this study are included within the article.

\section{Conflicts of Interest}

The authors declare that there is no conflict of interests regarding the publication of this paper.

\section{Acknowledgments}

This work was supported by project grants from the National Natural Science Foundation of China (grant Nos. 81400882, 81771159, 81571047, and 81500982) and Science Foundation Projects for Young Scientists of Hubei (grant No. 2017CFB171).

\section{Supplementary Materials}

Supplementary Table 1: study population. Supplementary Figure 1: the rooms and apparatus used in the MWM test and the division of quadrants and platforms. (A) The rooms and apparatus used in the MWM test. The MWM test was conducted in two separate rooms: test room and computer room. In the test room, there was a round and steel pool, which was filled up with water. Four graphic signals were hung on the walls as visual cues for the navigation of mice in the MWM. Swimming activity of each mouse was tracked via a camera mounted overhead and was analysed by AVTAS v3.3, an automated video-tracking system. The data was recorded automatically in a computer, which contains this system and was put in the computer room. (B) The background of the swimming path recorded by the videotracking system. By adding powdered milk, the water was rendered opaque. A platform (diametric distance, $10 \mathrm{~cm}$ ) was placed in the target quadrant and was $1.0 \mathrm{~cm}$ lower than the water level. (C) The quadrants and platforms divided automatically by the video-tracking system. Four platforms (platforms (1), (2), (3), and (4)) and four quadrants (quadrants $5,6,7$, and 8) were generated automatically, and platform (2) and quadrant 6 were defined as the target platform (marked by a black circle) and target quadrant (marked by red line), respectively. (D) The recorded swimming path shown in the manuscript without background. The target quadrant was marked by a red line. (Supplementary Materials)

\section{References}

[1] L. X. Lu, J. H. Yon, L. B. Carter, and V. Jevtovic-Todorovic, "General anesthesia activates BDNF-dependent neuroapoptosis in the developing rat brain," Apoptosis, vol. 11, no. 9, pp. 1603-1615, 2006.

[2] V. Jevtovic-Todorovic, R. E. Hartman, Y. Izumi et al., "Early exposure to common anesthetic agents causes widespread neurodegeneration in the developing rat brain and persistent learning deficits," The Journal of Neuroscience, vol. 23, no. 3, pp. 876-882, 2003. 
[3] C. Ikonomidou, F. Bosch, M. Miksa et al., "Blockade of NMDA receptors and apoptotic neurodegeneration in the developing brain," Science, vol. 283, no. 5398, pp. 70-74, 1999.

[4] A. M. Brambrink, A. S. Evers, M. S. Avidan et al., "Isofluraneinduced neuroapoptosis in the neonatal rhesus macaque brain," Anesthesiology, vol. 112, no. 4, pp. 834-841, 2010.

[5] C. E. Creeley, K. T. Dikranian, G. A. Dissen, S. A. Back, J. W. Olney, and A. M. Brambrink, "Isoflurane-induced apoptosis of neurons and oligodendrocytes in the fetal rhesus macaque brain," Anesthesiology, vol. 120, no. 3, pp. 626-638, 2014.

[6] A. M. Brambrink, S. A. Back, A. Riddle et al., "Isofluraneinduced apoptosis of oligodendrocytes in the neonatal primate brain," Annals of Neurology, vol. 72, no. 4, pp. 525535, 2012.

[7] J. Raper, J. C. De Biasio, K. L. Murphy, M. C. Alvarado, and M. G. Baxter, "Persistent alteration in behavioural reactivity to a mild social stressor in rhesus monkeys repeatedly exposed to sevoflurane in infancy," British Journal of Anaesthesia, vol. 120, no. 4, pp. 761-767, 2018.

[8] W. Slikker, X. Zou, C. E. Hotchkiss et al., "Ketamine-induced neuronal cell death in the perinatal rhesus monkey," Toxicological Sciences, vol. 98, no. 1, pp. 145-158, 2007.

[9] C. Creeley, K. Dikranian, G. Dissen, L. Martin, J. Olney, and A. Brambrink, "Propofol-induced apoptosis of neurones and oligodendrocytes in fetal and neonatal rhesus macaque brain," British Journal of Anaesthesia, vol. 110, Supplement 1, pp. i29i38, 2013.

[10] L. Vutskits and Z. Xie, "Lasting impact of general anaesthesia on the brain: mechanisms and relevance," Nature Reviews Neuroscience, vol. 17, no. 11, pp. 705-717, 2016.

[11] A. J. Davidson, "Neurotoxicity and the need for anesthesia in the newborn: does the emperor have no clothes?," Anesthesiology, vol. 116, no. 3, pp. 507-509, 2012.

[12] A. J. Davidson and L. S. Sun, "Clinical evidence for any effect of anesthesia on the developing brain," Anesthesiology, vol. 128, no. 4, pp. 840-853, 2018.

[13] J. X. Mazoit, P. Roulleau, and C. Baujard, "Isoflurane-induced neuroapoptosis in the neonatal rhesus macaque brain: isoflurane or ischemia-reperfusion?," Anesthesiology, vol. 113, no. 5, pp. 1245-1246, 2010.

[14] R. D. Sanders, D. Andropoulos, D. Ma, and M. Maze, "Theseus, the labyrinth, and the minotaur of anaesthetic-induced developmental neurotoxicity," British Journal of Anaesthesia, vol. 119, no. 3, pp. 453-455, 2017.

[15] L. Vutskits and J. W. Sall, "Reproducibility of science and developmental anaesthesia neurotoxicity: a tale of two cities," British Journal of Anaesthesia, vol. 119, no. 3, pp. 451-452, 2017.

[16] L. S. Sun, G. Li, T. L. Miller et al., "Association between a single general anesthesia exposure before age 36 months and neurocognitive outcomes in later childhood," JAMA, vol. 315 , no. 21, pp. 2312-2320, 2016.

[17] P. Glatz, R. H. Sandin, N. L. Pedersen, A. K. Bonamy, L. I. Eriksson, and F. Granath, "Association of anesthesia and surgery during childhood with long-term academic performance," JAMA Pediatrics, vol. 171, no. 1, article e163470, 2017.

[18] J. D. O'Leary, M. Janus, E. Duku et al., "Influence of surgical procedures and general anesthesia on child development before primary school entry among matched sibling pairs," JAMA Pediatrics, vol. 173, no. 1, pp. 29-36, 2019.

[19] A. J. Davidson, N. Disma, J. C. de Graaff et al., "Neurodevelopmental outcome at 2 years of age after general anaesthesia and awake-regional anaesthesia in infancy (GAS): an international multicentre, randomised controlled trial," The Lancet, vol. 387, no. 10015, pp. 239-250, 2016.

[20] M. E. McCann, J. C. de Graaff, L. Dorris et al., "Neurodevelopmental outcome at 5 years of age after general anaesthesia or awake-regional anaesthesia in infancy (GAS): an international, multicentre, randomised, controlled equivalence trial," The Lancet, vol. 393, no. 10172, pp. 664-677, 2019.

[21] D. O. Warner, M. J. Zaccariello, S. K. Katusic et al., "Neuropsychological and behavioral outcomes after exposure of young children to procedures requiring general anesthesia: the Mayo Anesthesia Safety in Kids (MASK) study," Anesthesiology, vol. 129, no. 1, pp. 89-105, 2018.

[22] M. J. Zaccariello, R. D. Frank, M. Lee et al., "Patterns of neuropsychological changes after general anaesthesia in young children: secondary analysis of the Mayo Anesthesia Safety in Kids study," British Journal of Anaesthesia, vol. 122, no. 5, pp. 671681, 2019.

[23] S. L. Patterson, T. Abel, T. A. Deuel, K. C. Martin, J. C. Rose, and E. R. Kandel, "Recombinant BDNF rescues deficits in basal synaptic transmission and hippocampal LTP in BDNF knockout mice," Neuron, vol. 16, no. 6, pp. 11371145, 1996.

[24] A. R. Santos, D. Comprido, and C. B. Duarte, "Regulation of local translation at the synapse by BDNF," Progress in Neurobiology, vol. 92, no. 4, pp. 505-516, 2010.

[25] R. S. Duman, "Synaptic plasticity and mood disorders," Molecular Psychiatry, vol. 7, Supplement 1, pp. S29-S34, 2002.

[26] P. Bekinschtein, M. Cammarota, I. Izquierdo, and J. H. Medina, "Reviews: BDNF and memory formation and storage," The Neuroscientist, vol. 14, no. 2, pp. 147-156, 2008.

[27] B. P. Head, H. H. Patel, I. R. Niesman, J. C. Drummond, D. M. Roth, and P. M. Patel, "Inhibition of p75 neurotrophin receptor attenuates isoflurane-mediated neuronal apoptosis in the neonatal central nervous system," Anesthesiology, vol. 110, no. 4, pp. 813-825, 2009.

[28] B. P. Lemkuil, B. P. Head, M. L. Pearn, H. H. Patel, J. C. Drummond, and P. M. Patel, "Isoflurane neurotoxicity is mediated by $\mathrm{p} 75^{\mathrm{NTR}}$-RhoA activation and actin depolymerization," Anesthesiology, vol. 114, no. 1, pp. 49-57, 2011.

[29] M. L. Pearn, Y. Hu, I. R. Niesman et al., "Propofol neurotoxicity is mediated by p75 neurotrophin receptor activation," Anesthesiology, vol. 116, no. 2, pp. 352-361, 2012.

[30] J. Wu, B. Bie, and M. Naguib, "Epigenetic manipulation of brain-derived neurotrophic factor improves memory deficiency induced by neonatal anesthesia in rats," Anesthesiology, vol. 124, no. 3, pp. 624-640, 2016.

[31] S. Michan, Y. Li, M. M.-H. Chou et al., "SIRT1 is essential for normal cognitive function and synaptic plasticity," The Journal of Neuroscience, vol. 30, no. 29, pp. 9695-9707, 2010.

[32] J. Gao, W. Y. Wang, Y. W. Mao et al., "A novel pathway regulates memory and plasticity via SIRT1 and miR-134," Nature, vol. 466, no. 7310, pp. 1105-1109, 2010.

[33] H. Jeong, D. E. Cohen, L. Cui et al., "Sirt1 mediates neuroprotection from mutant huntingtin by activation of the TORC1 and CREB transcriptional pathway," Nature Medicine, vol. 18, no. 1, pp. 159-165, 2012.

[34] M. Jiang, J. Wang, J. Fu et al., "Neuroprotective role of Sirt1 in mammalian models of Huntington's disease through activation of multiple Sirtl targets," Nature Medicine, vol. 18, no. 1, pp. 153-158, 2012. 
[35] A. Z. Herskovits and L. Guarente, "SIRT1 in neurodevelopment and brain senescence," Neuron, vol. 81, no. 3, pp. 471483, 2014.

[36] B. A. Q. Gomes, J. P. B. Silva, C. F. R. Romeiro et al., "Neuroprotective Mechanisms of Resveratrol in Alzheimer's Disease: Role of SIRT1," Oxidative Medicine and Cellular Longevity, vol. 2018, Article ID 8152373, 15 pages, 2018.

[37] B. Wang, S. Ge, W. Xiong, and Z. Xue, "Effects of resveratrol pretreatment on endoplasmic reticulum stress and cognitive function after surgery in aged mice," BMC Anesthesiology, vol. 18, no. 1, p. 141, 2018.

[38] X. M. Li, M. T. Zhou, X. M. Wang, M. H. Ji, Z. Q. Zhou, and J. J. Yang, "Resveratrol pretreatment attenuates the isoflurane-induced cognitive impairment through its antiinflammation and -apoptosis actions in aged mice," Journal of Molecular Neuroscience, vol. 52, no. 2, pp. 286-293, 2014.

[39] W. Hu, E. Yang, J. Ye, W. Han, and Z. L. Du, "Resveratrol protects neuronal cells from isoflurane-induced inflammation and oxidative stress-associated death by attenuating apoptosis via Akt/p38 MAPK signaling," Experimental and Therapeutic Medicine, vol. 15, no. 2, pp. 1568-1573, 2018.

[40] X. Shen, Y. Dong, Z. Xu et al., "Selective anesthesia-induced neuroinflammation in developing mouse brain and cognitive impairment," Anesthesiology, vol. 118, no. 3, pp. 502-515, 2013.

[41] X. Wang, Y. Dong, Y. Zhang, T. Li, and Z. Xie, "Sevoflurane induces cognitive impairment in young mice via autophagy," PLoS One, vol. 14, no. 5, article e0216372, 2019.

[42] G. Tao, J. Zhang, L. Zhang et al., "Sevoflurane induces tau phosphorylation and glycogen synthase kinase $3 \beta$ activation in young mice," Anesthesiology, vol. 121, no. 3, pp. 510-527, 2014.

[43] J. Zhang, Y. Dong, C. Zhou, Y. Zhang, and Z. Xie, “Anesthetic sevoflurane reduces levels of hippocalcin and postsynaptic density protein 95," Molecular Neurobiology, vol. 51, no. 3, pp. 853-863, 2015.

[44] K. K. S. Narasimhan, D. Jayakumar, P. Velusamy et al., "Morinda citrifolia and its active principle scopoletin mitigate protein aggregation and neuronal apoptosis through augmenting the DJ-1/Nrf2/ARE signaling pathway," Oxidative Medicine and Cellular Longevity, vol. 2019, Article ID 2761041, 13 pages, 2019.

[45] X. Zhang, X. Xin, Y. Dong et al., "Surgical incision-induced nociception causes cognitive impairment and reduction in synaptic NMDA receptor 2B in mice," The Journal of Neuroscience, vol. 33, no. 45, pp. 17737-17748, 2013.

[46] A. V. Terry Jr., "Spatial navigation (water maze) tasks," in Methods of Behavior Analysis in Neuroscience, J. J. Buccafusco, Ed., pp. 267-280, CRC Press, Boca Raton, FL, USA, 2nd edition, 2009.

[47] X. Feng, N. Liang, D. Zhu et al., "Resveratrol inhibits $\beta$-Amyloid-Induced neuronal apoptosis through regulation of SIRT1ROCK1 signaling pathway," PLoS One, vol. 8, no. 3, article e59888, 2013.

[48] P. Peñalver, E. Belmonte-Reche, N. Adán et al., “Alkylated resveratrol prodrugs and metabolites as potential therapeutics for neurodegenerative diseases," European Journal of Medicinal Chemistry, vol. 146, pp. 123-138, 2018.

[49] Y. Hou, K. Wang, W. Wan, Y. Cheng, X. Pu, and X. Ye, "Resveratrol provides neuroprotection by regulating the JAK2/STAT3/PI3K/AKT/mTOR pathway after stroke in rats," Genes \& Diseases, vol. 5, no. 3, pp. 245-255, 2018.
[50] W. Lv, J. Zhang, A. Jiao, B. Wang, B. Chen, and J. Lin, "Resveratrol attenuates hIAPP amyloid formation and restores the insulin secretion ability in hIAPP-INS1 cell line via enhancing autophagy," Canadian Journal of Physiology and Pharmacology, vol. 97, no. 2, pp. 82-89, 2019.

[51] Q. Chen, S. Ganapathy, K. P. Singh, S. Shankar, and R. K. Srivastava, "Resveratrol induces growth arrest and apoptosis through activation of FOXO transcription factors in prostate cancer cells," PLoS One, vol. 5, no. 12, article e15288, 2010.

[52] J. Xiao, X. Wang, Y. Wu et al., "Synergistic effect of resveratrol and HSV-TK/GCV therapy on murine hepatoma cells," Cancer Biology \& Therapy, vol. 20, no. 2, pp. 183-191, 2019.

[53] L. Zocchi and P. Sassone-Corsi, "SIRT1-mediated deacetylation of MeCP2 contributes to BDNF expression," Epigenetics, vol. 7, no. 7, pp. 695-700, 2012.

[54] N. E. Clifton, D. Cameron, S. Trent, L. H. Sykes, K. L. Thomas, and J. Hall, "Hippocampal regulation of postsynaptic density Homer1 by associative learning," Neural Plasticity, vol. 2017, Article ID 5959182, 11 pages, 2017.

[55] I. Ehrlich and R. Malinow, "Postsynaptic density 95 controls AMPA receptor incorporation during long-term potentiation and experience-driven synaptic plasticity," The Journal of Neuroscience, vol. 24, no. 4, pp. 916-927, 2004.

[56] J. C. Beique and R. Andrade, "PSD-95 regulates synaptic transmission and plasticity in rat cerebral cortex," The Journal of Physiology, vol. 546, no. 3, pp. 859-867, 2003.

[57] K. Han and E. Kim, "Synaptic adhesion molecules and PSD95," Progress in Neurobiology, vol. 84, no. 3, pp. 263-283, 2008.

[58] J. Fourneau, M. H. Canu, C. Cieniewski-Bernard, B. Bastide, and E. Dupont, "Synaptic protein changes after a chronic period of sensorimotor perturbation in adult rats: a potential role of phosphorylation/O-GlcNAcylation interplay," Journal of Neurochemistry, vol. 147, no. 2, pp. 240-255, 2018.

[59] M. Martineau, R. E. Guzman, C. Fahlke, and J. Klingauf, "VGLUT1 functions as a glutamate/proton exchanger with chloride channel activity in hippocampal glutamatergic synapses," Nature Communications, vol. 8, no. 1, p. 2279, 2017.

[60] J. H. Zimering, Y. Dong, F. Fang, L. Huang, Y. Zhang, and Z. Xie, "Anesthetic sevoflurane causes rho-dependent filopodial shortening in mouse neurons," PLoS One, vol. 11, no. 7, article e0159637, 2016.

[61] H. Lu, N. Liufu, Y. Dong et al., "Sevoflurane acts on ubiquitination-proteasome pathway to reduce postsynaptic density 95 protein levels in young mice," Anesthesiology, vol. 127, no. 6, pp. 961-975, 2017.

[62] M. Korte, O. Griesbeck, C. Gravel et al., "Virus-mediated gene transfer into hippocampal CA1 region restores long-term potentiation in brain-derived neurotrophic factor mutant mice," Proceedings of the National Academy of Sciences of the United States of America, vol. 93, no. 22, pp. 12547-12552, 1996.

[63] G. Leal, D. Comprido, and C. B. Duarte, "BDNF-induced local protein synthesis and synaptic plasticity," Neuropharmacology, vol. 76, Part C, pp. 639-656, 2014.

[64] Y. Wang, W. Rao, C. Zhang et al., "Scaffolding protein Homer1a protects against NMDA-induced neuronal injury," Cell Death \& Disease, vol. 6, no. 8, article e1843, 2015.

[65] M. Jia, W. X. Liu, J. J. Yang et al., "Role of histone acetylation in long-term neurobehavioral effects of neonatal exposure to sevoflurane in rats," Neurobiology of Disease, vol. 91, pp. 209-220, 2016. 
[66] C. M. Stary, X. Sun, and R. G. Giffard, "Astrocytes protect against isoflurane neurotoxicity by buffering pro-brainderived neurotrophic factor," Anesthesiology, vol. 123, no. 4, pp. 810-819, 2015.

[67] C. H. Zhou, Y. H. Zhang, F. Xue et al., "Isoflurane exposure regulates the cell viability and BDNF expression of astrocytes via upregulation of TREK-1," Molecular Medicine Reports, vol. 16, no. 5, pp. 7305-7314, 2017.

[68] Y. K. Ryu, S. Khan, S. C. Smith, and C. D. Mintz, "Isoflurane impairs the capacity of astrocytes to support neuronal development in a mouse dissociated coculture model," Journal of Neurosurgical Anesthesiology, vol. 26, no. 4, pp. 363368,2014

[69] K.-W. Chen and L. Chen, "Epigenetic regulation of BDNF gene during development and diseases," International Journal of Molecular Sciences, vol. 18, no. 3, p. 571, 2017.

[70] N. N. Karpova, "Role of BDNF epigenetics in activitydependent neuronal plasticity," Neuropharmacology, vol. 76, Part C, pp. 709-718, 2014.

[71] L. Dalla Massara, H. P. Osuru, A. Oklopcic et al., "General anesthesia causes epigenetic histone modulation of c-Fos and brain-derived neurotrophic factor, target genes important for neuronal development in the immature rat hippocampus," Anesthesiology, vol. 124, no. 6, pp. 1311-1327, 2016.

[72] T. KhorshidAhmad, C. Acosta, C. Cortes, T. M. Lakowski, S. Gangadaran, and M. Namaka, "Transcriptional regulation of brain-derived neurotrophic factor (BDNF) by methyl CpG binding protein 2 (MeCP2): a novel mechanism for remyelination and/or myelin repair involved in the treatment of multiple sclerosis (MS)," Molecular Neurobiology, vol. 53, no. 2, pp. 1092-1107, 2016.

[73] X. Fang, Q. Han, S. Li, Y. Zhao, and A. Luo, "Chikusetsu saponin IVa attenuates isoflurane-induced neurotoxicity and cognitive deficits via SIRT1/ERK1/2 in developmental rats," American Journal of Translational Research, vol. 9, no. 9, pp. 4288-4299, 2017.

[74] A. R. Gomes, J. S. Yong, K. C. Kiew et al., "Sirtuin1 (SIRT1) in the acetylation of downstream target proteins," Methods in Molecular Biology, vol. 1436, pp. 169-188, 2016.

[75] Z. Wu and P. Zhao, "Epigenetic alterations in anesthesiainduced neurotoxicity in the developing brain," Frontiers in Physiology, vol. 9, p. 1024, 2018.

[76] T. Sen and N. Sen, "Isoflurane-induced inactivation of CREB through histone deacetylase 4 is responsible for cognitive impairment in developing brain," Neurobiology of Disease, vol. 96, pp. 12-21, 2016.

[77] S. M. Joksimovic, H. P. Osuru, A. Oklopcic, M. P. Beenhakker, V. Jevtovic-Todorovic, and S. M. Todorovic, "Histone deacetylase inhibitor entinostat (MS-275) restores anesthesia-induced alteration of inhibitory synaptic transmission in the developing rat hippocampus," Molecular Neurobiology, vol. 55, no. 1, pp. 222-228, 2018.

[78] J. H. Kalin and J. A. Bergman, "Development and therapeutic implications of selective histone deacetylase 6 inhibitors," Journal of Medicinal Chemistry, vol. 56, no. 16, pp. 62976313, 2013.

[79] M. H. Keylor, B. S. Matsuura, and C. R. Stephenson, "Chemistry and biology of resveratrol-derived natural products," Chemical Reviews, vol. 115, no. 17, pp. 8976-9027, 2015.

[80] A. V. Witte, L. Kerti, D. S. Margulies, and A. Floel, "Effects of resveratrol on memory performance, hippocampal functional connectivity, and glucose metabolism in healthy older adults," The Journal of Neuroscience, vol. 34, no. 23, pp. 7862-7870, 2014.

[81] A. Alayev, S. M. Berger, and M. K. Holz, "Resveratrol as a novel treatment for diseases with $\mathrm{mTOR}$ pathway hyperactivation," Annals of the New York Academy of Sciences, vol. 1348, no. 1, pp. 116-123, 2015.

[82] A. L. Widlund, J. A. Baur, and O. Vang, "mTOR: more targets of resveratrol?," Expert Reviews in Molecular Medicine, vol. 15, 2013.

[83] Y. Wu and F. Liu, "Targeting mTOR: evaluating the therapeutic potential of resveratrol for cancer treatment," Anti-Cancer Agents in Medicinal Chemistry, vol. 13, no. 7, pp. 1032-1038, 2013.

[84] A. Sanches-Silva, L. Testai, S. F. Nabavi et al., "Therapeutic potential of polyphenols in cardiovascular diseases: regulation of mTOR signaling pathway," Pharmacological Research, vol. 152, article 104626, 2020.

[85] Q. Yu, C. L. Dai, Y. Zhang et al., "Intranasal insulin increases synaptic protein expression and prevents anesthesia-induced cognitive deficits through mTOR-eEF2 pathway," Journal of Alzheimer's Disease, vol. 70, no. 3, pp. 925-936, 2019.

[86] S. R. Arafa, C. L. LaSarge, R. Y. K. Pun, S. Khademi, and S. C. Danzer, "Self-reinforcing effects of mTOR hyperactive neurons on dendritic growth," Experimental Neurology, vol. 311, pp. 125-134, 2019.

[87] J. Xu, R. Mathena, M. Xu et al., "Early developmental exposure to general anesthetic agents in primary neuron culture disrupts synapse formation via actions on the mTOR pathway," International Journal of Molecular Sciences, vol. 19, no. 8, p. 2183, 2018.

[88] J. Xu, E. Kang, and C. D. Mintz, “Anesthetics disrupt brain development via actions on the mTOR pathway," Communicative \& Integrative Biology, vol. 11, no. 2, pp. 1-4, 2018.

[89] E. Kang, D. Jiang, Y. K. Ryu et al., "Early postnatal exposure to isoflurane causes cognitive deficits and disrupts development of newborn hippocampal neurons via activation of the mTOR pathway," PLoS Biology, vol. 15, no. 7, article e2001246, 2017.

[90] H. Tan, C. L. Li, L. Zhang, Z. J. Yang, X. Zhao, and Y. W. Wang, "Sevoflurane inhibits the phosphorylation of ribosomal protein S6 in neonatal rat brain," International Journal of Clinical and Experimental Medicine, vol. 8, no. 9, pp. 14816-14826, 2015.

[91] M. S. Abdel-Maksoud, M. I. El-Gamal, D. R. Benhalilou, S. Ashraf, S. A. Mohammed, and C.-. H. Oh, "Mechanistic/mammalian target of rapamycin: recent pathological aspects and inhibitors," Medicinal Research Reviews, vol. 39, no. 2, pp. 631-664, 2019.

[92] N. Takei, N. Inamura, M. Kawamura et al., "Brain-derived neurotrophic factor induces mammalian target of rapamycindependent local activation of translation machinery and protein synthesis in neuronal dendrites," The Journal of Neuroscience, vol. 24, no. 44, pp. 9760-9769, 2004.

[93] A. P. Singh, R. Singh, S. S. Verma et al., "Health benefits of resveratrol: evidence from clinical studies," Medicinal Research Reviews, vol. 39, no. 5, pp. 1851-1891, 2019.

[94] S. V. Narayanan, K. R. Dave, I. Saul, and M. A. Perez-Pinzon, "Resveratrol preconditioning protects against cerebral ischemic injury via nuclear erythroid 2-related factor 2," Stroke, vol. 46, no. 6, pp. 1626-1632, 2015. 